\title{
ESTIMATION OF PORTFOLIO EFFICIENCY CONSIDERING SOCIAL RESPONSIBILITY: EVIDENCE FROM THE MULTI-HORIZON DIVERSIFICATION DEA
}

\author{
Tiantian Ren ${ }^{1}$, Zhongbao Zhou ${ }^{1}$ and Helu XiaO ${ }^{2, *}$
}

\begin{abstract}
With the introduction of the concept of social responsibility investment/green investment, more and more investors have realized the importance of such investment, which has prompted portfolio managers to more comprehensively consider both financial and non-financial performance of portfolios in different time horizons. DEA (Data Envelopment Analysis), as a data-driven evaluation approach, has been widely used in performance evaluation of portfolios. However, the existing studies are mostly limited to single-horizon problems, and the evaluation indicators are mostly financial indicators, while ignoring the impact of non-financial indicators (e.g., social responsibility indicators). More importantly, the input-output process of portfolios in the multi-horizon framework also needs to be clarified. In this paper, we first define the input-output process of portfolios from the multi-horizon perspective, and then propose the corresponding stochastic output possibility sets based on portfolio returns and social responsibility indicators. We use the expectation and variance measures to derive the deterministic estimation of the above stochastic sets, where the expectations and variances of portfolio returns and social responsibility indicators are all regarded as outputs. We construct the multi-horizon diversification DEA models both with and without social responsibility constraints. Finally, we select the 20 component stocks of China ESG100 index to illustrate the difference between the multi-horizon models and the single-horizon models, and further discuss the impact of social responsibility on the portfolio efficiency and its ranking. The empirical results show that compared with the single-horizon models, the proposed models can provide portfolio managers with an improvement strategy to balance the performance of portfolio returns and social responsibility indicators in different time horizons. Further, we also find that the social responsibility has a greater impact on the portfolio efficiency and its ranking, especially when the portfolio managers pay more attention to the social responsibility performance.
\end{abstract}

Mathematics Subject Classification. 90B30, 90B50, 90C30, 91G10.

Received May 10, 2020. Accepted February 18, 2021.

Keywords. Traditional DEA; Diversification DEA; Multi-horizon portfolio evaluation; Social responsibility; Mean-variance criterion.

1 School of Business Administration, Hunan University, Changsha 410082, P.R. China.

2 School of Business, Hunan Normal University, Changsha 410081, P.R. China.

*Corresponding author: xiaohelu1986@163.com 


\section{INTRODUCTION}

Currently, the global climate problem is serious and the human living environment has been greatly damaged. Therefore, the development of green investment is an inevitable choice to mitigate climate change and achieve sustainable development. To this end, the Chinese government has proposed the policies of "building a beautiful China" and "promoting a sound economic structure that facilitates green, low-carbon and circular development", which require our investment to focus on the harmonious coexistence of economic development and ecological environment. Socially responsibility investment/green investment encourages enterprises to actively undertake the social responsibility while pursuing the economic benefits, thereby bringing sustainable development value to investors and society. Because of the late start of social responsibility investment in China, many experts also suggest that the development environment for social responsibility investment should be optimized in terms of laws, policies, and evaluation systems. It can be seen that the study on the evaluation of portfolios with consideration of social responsibility is suitable for the requirements of social development and also has important practical guidance.

Although the portfolio evaluation has existed in academia for many years, the evaluation of social responsibility portfolios is still in the exploratory stage. Because the performance of social responsibility portfolios requires an integrated consideration of their performance in terms of economy, society, and environment, thus the input-output process often exhibits the characteristics of multiple inputs and multiple outputs. As an evaluation method based on multiple input and output indicators, DEA is considered an effective tool for addressing efficiency evaluation problems. This method does not need to specify the form of production function, effectively avoids the error of model setting, and can also provide an improvement benchmark for decision-maker units (DMUs). In recent years, DEA has been widely used in estimation of portfolio efficiency, among which traditional DEA and diversification DEA are two common methods to solve this problem.

Traditional DEA is indeed a simple and effective evaluation approach, because it uses linear programming technology to measure the efficiency of DMUs. There has been an extensive literature on the financial performance of conventional portfolios (e.g., mutual funds and hedge funds) by traditional DEA, which mostly adopts the financial indicators as the evaluation indicators. Murthi et al. [29] first applied a single output DEA model for estimating the portfolio efficiency, among which the transaction fees and the standard deviation of fund return are regarded as inputs and the expected return as the sole output. Basso and Funari [3] took different risk indicators of a portfolio as inputs and the expected return and stochastic dominance indicator as outputs, and then constructed a DEA model with multiple inputs and multiple outputs to estimate the efficiency of Italian funds. The above two seminal studies focus on measuring the performance of mutual funds, while others kinds of funds, such as hedge funds, are absent. To this end, Gregoriou et al. [18] first applied the traditional DEA model to evaluate the performance of hedge funds, and compared the results with these by the classical single index methods. Chen and Lin [12] used VaR and CVaR measures rather than the standard deviation measure shown in the above literature to describe the risk of portfolios, and then proposed the corresponding DEA models to estimate the portfolio efficiency, where the different risk indicators are treated as inputs and the expected return as an output. Although the traditional DEA has been widely used in estimation of portfolio efficiency, its applicability still needs to be further justified and tested. Ding et al. [16] examined the applicability of DEA in the evaluation of portfolios with margin requirements. More in general, when the portfolio frontier is a concave function, Liu et al. [24] demonstrated the convergence of DEA frontier under the generalized return-risk framework, and provided the theoretical support for the application of DEA in the portfolio evaluation. However, when it comes to some nonconvex portfolio optimization problems (see, e.g., the cardinality constrained portfolio optimization problem), traditional DEA models will fail to approximate the portfolio efficiency since they have made the assumption of concavity for the portfolio frontier. To address this problem, Zhou et al. [34] proposed a segmented DEA model to deal with the performance evaluation of portfolios with nonconvex cardinality constraints, and also proved that the segmented DEA frontier can better to approach the portfolio frontier. For more studies about the estimation of portfolio efficiency via traditional DEA, readers may refer to Choi and Min [15], Basso and Funari [6], Chen et al. [13], and so on. 
Although the calculation of traditional DEA is relatively simple, many scholars question the ability to diversify risks because it ignores the correlation between portfolios. Since Markowitz [27] pointed that the portfolio of assets can diversify risks, many researchers have begun to construct diversification DEA models to estimate the portfolio efficiency. Briec et al. [10] proposed a diversification DEA model under the mean-variance criterion, and further distinguished the portfolio efficiency and the allocation efficiency. Subsequently, for the portfolio returns with non-normal distribution, Joro and $\mathrm{Na}[20]$ provided a diversification DEA model within the framework of mean-variance-skewness to investigate the impact of skewness on the portfolio efficiency. What is more, Briec et al. [11] continued in this direction and established a diversification DEA model with high-order moment constraints based on the directional distance function measure, and theoretically proved the availability of the global optimal solution to the proposed model. And Lamb and Tee [21] not only proposed a generalized diversification DEA model based on multiple input and multiple output indicators, but also systematically investigated the relationship between the portfolio diversification, coherent risk measure, and stochastic dominance. As an extension of the above studies, Branda [8] used the directional distance function measure to construct three more generalized diversification DEA models under the return-risk framework, which can deal with the evaluation problems with negative inputs and outputs. To the best of our knowledge, the above literature mostly takes risk as one input and return as one output, while this assumption is actually not congruent with the real investment process. The work of Zhou et al. [36] proposed a novel input-output process of portfolios in accordance with the actual investment process (i.e., the input is the initial wealth and the output is the terminal wealth), and further investigated the relationship between traditional DEA and diversification DEA. This extension is interesting because the inputs and outputs for evaluating portfolios are from the real investment process, which partly provides a theoretical explanation for adopting efficiency measures from production theory in portfolio evaluation. In addition to these mentioned developments, for more studies about diversification DEA, readers may refer to Lozano and Gutiérrez [25], Tarnaud and Leleu [31], and Lin and Li [22].

The above studies focus on the portfolios from the traditional investment perspective, i.e., portfolio managers only concern about the financial performance of portfolios and ignore the social responsibility performance of portfolios, which is inconsistent with the stated goals of green/social responsibility investment. More recently, an increasing research has begun to focus on social responsible criteria in portfolio performance evaluation. As far as we know, the existing relevant studies are mainly carried out from the following aspects. First, some scholars have investigated what evaluation indicators should be used to measure the performance of green/socially responsible funds. Basso and Funari [4] first integrated the return, risk, and social responsibility levels of funds to construct the DEA model, so as to discuss the portfolio efficiency of social responsibility funds. Belu [7] applied DEA to measure the performance of publicly listed corporations and investigated the relationship between economic performance and corporate social responsibility of a company, where some financial indicators (i.e., return on assets, return on equity and yearly stock return) were treated as inputs and sustainability scores as outputs. Tsolas and Charles [32] used both slacks-based DEA and RAM-BCC models to assess the performance of green exchange-traded funds, where only some financial indicators were considered as the inputs and outputs of DEA models. Allevi et al. [2] used DEA to evaluate the performance of green funds, among which environmental and financial indicators were both considered. Second, some scholars have begun to discuss the differences between the performance of socially responsible funds and other kinds of traditional funds. For instance, Pérez Gladish et al. [30] combined DEA and stochastic dominance theory to analyze the difference in efficiency between traditional funds and social responsibility funds. The same concern also motivated Basso and Funari [5] that used constant and variable returns to scale DEA models to investigate the difference in performance between social responsibility funds and traditional funds. Abdelsalam et al. [1] analyzed the performance persistence of Islamic and social responsibility funds by using DEA, FDH (Free Disposal Hull) and partial frontier approaches. Recently, a DEA frontier improvement approach was proposed by Zhou et al. [35] to measure the performance of mutual funds with and without consideration of sustainability information disclosure. Third, some scholars have believed that there are differences in the relative efficiency across different investment regions. To this end, Makni et al. [26] proposed a meta-frontier DEA approach to evaluate the portfolio efficiency of social responsibility funds during crisis and growth periods and across six investment regions. Finally, some scholars 
have also considered that the management of socially responsible funds can be treated as a two-stage process with operational management and portfolio management rather than the above single-stage process only with portfolio management. For instance, Galagedera [17] considered the management of socially responsible funds as two processes, including operational management and portfolio management, and then proposed a two-stage DEA model with consideration of the social responsibility level of funds.

From the above lines of research, we find that most of the above studies that consider the performance of social responsibility funds are still limited to static problems, i.e., they just focus on the static performance of portfolios rather than the comprehensive performance over multiple time horizons. In addition, the evaluation methodology used is also restricted to traditional DEA that cannot consider the correlation between portfolios. However, for portfolio managers, they often need to combine the performance of portfolios over different time horizons, and then formulate a global management strategy to attract more investors to buy the portfolios they manage. In addition to this, since the correlation between portfolios cannot be ignored, diversification DEA may be more applicable. The basis for solving these problems is that the input-output process of portfolios within the multi-horizon framework should be clarified, which is also one of the work of this paper.

Referring to the works of Morey and Morey [28] and Briec and Kerstens [9], we first clarify the inputoutput process of portfolios under the multi-horizon framework, and then construct the stochastic output possibility sets both with and without social responsibility constraints. Furthermore, we use the expectation and variance measures to estimate the stochastic constraints of the above stochastic output possibility sets, and then construct the corresponding deterministic output possibility set under the mean-variance criterion. Based on the proposed input-output process, we consider that the expectations and variances of portfolio returns and social responsibility data should be treated as output indicators, because they are all evaluation indicators derived from portfolio returns and social responsibility data. More specifically, the expectations are desirable outputs and the variances are undesirable outputs. To address the problem of negative and undesirable outputs, we use the popular direction distance function measure to construct the multi-horizon diversification DEA models under different situations. Further, we take 20 component stocks of China ESG100 index as DMUs to verify the rationality and effectiveness of the proposed models, and then discuss the difference between the multi-horizon models and the existing single-horizon models. In addition to this, we also investigate the impact of social responsibility on the portfolio efficiency and its ranking. The empirical results show that, compared with the single-horizon models, the proposed multi-horizon diversification DEA models cannot only improve the expectations and variances of portfolio returns but also improve these of social responsibility indicators. What is more, the results further indicate that the social responsibility has a greater impact on the portfolio efficiency and its ranking, especially when portfolio managers focus more on the performance of social responsibility.

The remainder of this paper is organized as follows. In Section 2, we first clarify the input-output process of portfolios with and without consideration of social responsibility constraints, and further build the multi-horizon models under different situations. In Section 3, we carry out an empirical analysis to verify the rationality and validity of the proposed models. Finally, we conclude our paper here.

\section{Estimation of PORTFOLIO EFFICIENCY FROM A MULTi-HORIZON PERSPECTIVE}

Suppose that there are $n$ portfolios to be evaluated in the financial market and decision-makers can observe the return series of portfolios from time 0 to time $t$, where $t=1,2, \ldots, T$. The return series of the $j$-th portfolio is recorded as a random variable $r_{0, t}^{j}$, where $j=1,2, \ldots, n$ and $t=1,2, \ldots, T$. In addition to this, decisionmakers can also observe the social responsibility series of portfolios in different time horizons. Similarly, for the $j$-th portfolio under evaluation, the social responsibility series from 0 to $t$ is regarded as a random variable

$s_{0, t}^{j}$, where $j=1,2, \ldots, n$ and $t=1,2, \ldots, T$. Based on the above assumptions, we will clarify the input-output process of portfolios from the multi-horizon perspective, and then construct a multi-horizon diversification DEA model integrating the performance of portfolios in different time horizons. Referring to the work of Zhou et al. [36], by unitizing the initial wealth of portfolios, for the $d$-th portfolio under evaluation, the input-output 


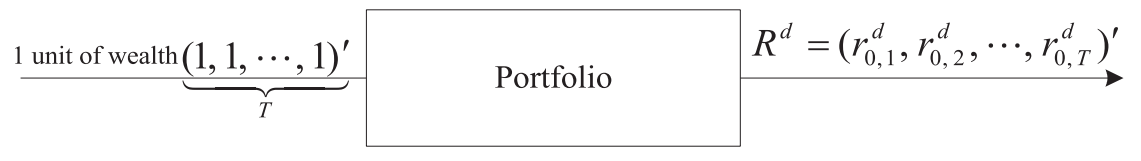

(a)

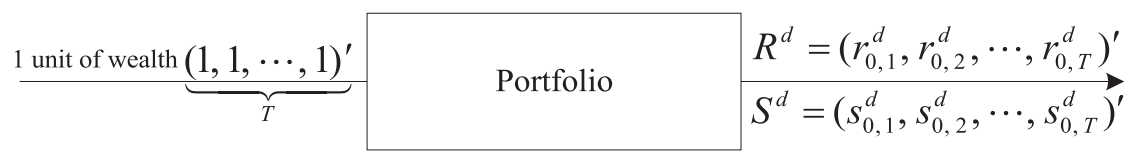

(b)

FigURE 1. The input-output process of portfolios under the multi-horizon perspective.

process of portfolios under the multi-horizon perspective can be constructed by using portfolio returns and social responsibility indicators. The details are as follows:

Under the input-output process shown in Figure 1a, the input of portfolios is 1 unit wealth, and the output is the portfolio return in each time horizon. Under this input-output framework, decision-makers only consider the financial indicator (i.e., the portfolio return) of portfolios. Compared with that in Figure 1a, the input-output process shown in Figure 1b integrates the financial and non-financial indicators (i.e., the portfolio return and the social responsibility) to construct the input-output process of portfolios. Based on the above two input-output processes, we will build the production possibility sets in the following.

\subsection{Multi-horizon diversification DEA model without considering social responsibility}

Since the initial wealth of portfolios has been standardized, therefore, we will build the output possibility set of portfolios based on the portfolio returns. Note that $r_{0, t}^{j}$ represents the portfolio return at a given time horizon, strictly speaking, the effect of time discounting on the portfolio returns should be considered here. Let the risk-free rate $r_{f}$ be the discount rate, applying the classical convexity assumption, then the discounted value of portfolio returns at different time horizons can be expressed as $\widetilde{R}=\sum_{j=1}^{n} \lambda_{j}\left(\frac{r_{0,1}^{j}}{1+r_{f}}, \frac{r_{0,2}^{j}}{\left(1+r_{f}\right)^{2}}, \ldots, \frac{r_{0, T}^{j}}{\left(1+r_{f}\right)^{T}}\right)^{\prime}$, where $\sum_{j=1}^{n} \lambda_{j}=1, \lambda_{j} \geq 0, j=1,2, \ldots, n, \widetilde{R}=\left(\widetilde{r}_{0,1}, \widetilde{r}_{0,2}, \ldots, \widetilde{r}_{0, T}\right)^{\prime}$, and $\widetilde{r}_{0, t}=\sum_{j=1}^{n} \lambda_{j} \frac{r_{0, t}^{j}}{\left(1+r_{f}\right)^{t}}, t=1,2, \ldots, T$. However, we find that the discounted value of portfolio return vector $\widetilde{R}$ can be converted to the original portfolio return vector $R=\sum_{j=1}^{n} \lambda_{j}\left(r_{0,1}^{j}, r_{0,2}^{j}, \ldots, r_{0, T}^{j}\right)^{\prime}$ due to the relationship that $\widetilde{r}_{0, t} \times\left(1+r_{f}\right)^{t}=\sum_{j=1}^{n} \lambda_{j} r_{0, t}^{j}=r_{0, t}$. More importantly, DEA is data-driven approach for measuring the relative efficiencies of peer DMUs, that is, the time discounting does not affect the evaluation results, because they are all relative evaluations under the same criteria. This is why the time discounting is not considered in the existing studies about the multi-horizon DEA portfolio evaluation (see, e.g., $[9,23,28]$ ). For the above reasons, when portfolio managers only pay attention to the portfolio returns, using the original portfolio returns and input-output process shown Figure 1a, we can construct the following stochastic output possibility set of portfolios.

$$
\Phi_{1}=\left\{R \mid \begin{array}{l}
R=\sum_{j=1}^{n} \lambda_{j}\left(r_{0,1}^{j}, r_{0,2}^{j}, \ldots, r_{0, T}^{j}\right)^{\prime}, \\
\sum_{j=1}^{n} \lambda_{j}=1, \lambda_{j} \geq 0, j=1,2, \ldots, n .
\end{array}\right\} .
$$

Although Set (2.1) is derived from the actual input-output process of portfolios, it is difficult for evaluators to directly estimate the portfolio efficiency based on Set (2.1) because of the randomness of portfolio returns. In the following, we will use some classical return and risk measures (i.e., the expectation and variance measures) 
to estimate the stochastic constraints in Set (2.1). Under the classical mean-variance framework, when the expectation and variance of portfolio returns satisfy the strong free disposability assumption, the following deterministic output possibility set of portfolios within the diversification DEA framework can be constructed here.

$$
\mathrm{PPS}_{1}=\left\{\begin{array}{l|l}
(E(R), \operatorname{Var}(R)) & \begin{array}{l}
E(R) \leq E\left[\sum_{j=1}^{n} \lambda_{j}\left(r_{0,1}^{j}, r_{0,2}^{j}, \ldots, r_{0, T}^{j}\right)^{\prime}\right], \\
\operatorname{Var}(R) \geq \operatorname{Var}\left[\sum_{j=1}^{n} \lambda_{j}\left(r_{0,1}^{j}, r_{0,2}^{j}, \ldots, r_{0, T}^{j}\right)^{\prime}\right], \\
\sum_{j=1}^{n} \lambda_{j}=1, \lambda_{j} \geq 0, j=1,2, \ldots, n .
\end{array}
\end{array}\right\}
$$

As shown in $\mathrm{PPS}_{1}$, we can find that the output possibility set of diversification DEA has dealt fully with portfolio diversification compared with that of traditional DEA (see, e.g., $[8,10,21,25]$ ). To further show the difference between diversification DEA and traditional DEA, we also provide the output possibility set of portfolios under the traditional DEA framework.

$$
\overline{\operatorname{PPS}_{1}}=\left\{\begin{array}{l|l}
(E(R), \operatorname{Var}(R)) & \begin{array}{l}
E(R) \leq \sum_{j=1}^{n} \lambda_{j} E\left(r_{0,1}^{j}, r_{0,2}^{j}, \ldots, r_{0, T}^{j}\right)^{\prime}, \\
\operatorname{Var}(R) \geq \sum_{j=1}^{n} \lambda_{j} \operatorname{Var}\left(r_{0,1}^{j}, r_{0,2}^{j}, \ldots, r_{0, T}^{j}\right)^{\prime} \\
\sum_{j=1}^{n} \lambda_{j}=1, \lambda_{j} \geq 0, j=1,2, \ldots, n .
\end{array}
\end{array}\right\}
$$

According to the expressions of $\mathrm{PPS}_{1}$ and $\overline{\mathrm{PPS}_{1}}$, we can obtain the following conclusion by using the convexity and concavity of the risk and return measures.

$$
\left\{\begin{array}{l}
E\left[\sum_{j=1}^{n} \lambda_{j}\left(r_{0,1}^{j}, r_{0,2}^{j}, \ldots, r_{0, T}^{j}\right)^{\prime}\right]=\sum_{j=1}^{n} \lambda_{j} E\left(r_{0,1}^{j}, r_{0,2}^{j}, \ldots, r_{0, T}^{j}\right)^{\prime}, \\
\operatorname{Var}\left[\sum_{j=1}^{n} \lambda_{j}\left(r_{0,1}^{j}, r_{0,2}^{j}, \ldots, r_{0, T}^{j}\right)^{\prime}\right] \leq \sum_{j=1}^{n} \lambda_{j} \operatorname{Var}\left(r_{0,1}^{j}, r_{0,2}^{j}, \ldots, r_{0, T}^{j}\right)^{\prime} .
\end{array}\right.
$$

Equation (2.4) indicates that $\overline{\mathrm{PPS}_{1}}$ is a subset of $\mathrm{PPS}_{1}$. That is to say, $\overline{\mathrm{PPS}_{1}}$ can be regarded as a linear estimation of $\mathrm{PPS}_{1}$. Clearly, the frontier constructed by $\mathrm{PPS}_{1}$ dominates that constructed by $\overline{\mathrm{PPS}_{1}}$. This is due to the importance of covariances among portfolios, which is ignored in the traditional DEA approach.

In the following, we will build the corresponding diversification DEA models based on $\mathrm{PPS}_{1}$. As shown in $\mathrm{PPS}_{1}$, the expected return and variance are two evaluation indicators derived from the portfolio return, so it is more reasonable to use both as output indicators. More precisely, the expected return is regarded as a desirable output, and the variance is treated as an undesirable output, because decision-makers always hope that the expected return of a portfolio to be as large and its variance as small as possible. To address the undesirable output shown in $\mathrm{PPS}_{1}$, we use the classical directional distance function to measure the portfolio efficiency. For a given projection direction $\left(g_{E}^{R},-g_{V}^{R}\right)^{\prime}$, we assume that $\left(E\left(R^{d}\right)+\theta g_{E}^{R}\right.$, $\left.\operatorname{Var}\left(R^{d}\right)-\theta g_{V}^{R}\right) \in \mathrm{PPS}_{1}$, where $g_{E}^{R}=\left(g_{E}^{r_{1}}, g_{E}^{r_{2}}, \ldots, g_{E}^{r_{T}}\right)^{\prime}$ and $g_{V}^{R}=\left(g_{V}^{r_{1}}, g_{V}^{r_{2}}, \ldots, g_{V}^{r_{T}}\right)^{\prime}$. Then, the following diversification DEA model under 
output orientation can be constructed: $\theta_{1}^{d}=\max _{\theta}\left\{\theta \mid\left(E\left(R^{d}\right)+\theta g_{E}^{R}, \operatorname{Var}\left(R^{d}\right)-\theta g_{V}^{R}\right) \in \mathrm{PPS}_{1}\right\}$. To be specific, it can be expressed as

$$
\begin{aligned}
& \theta_{1}^{d}=\max \theta \\
& \text { s.t. }\left\{\begin{array}{l}
E\left[\sum_{j=1}^{n} \lambda_{j}\left(r_{0,1}^{j}, r_{0,2}^{j}, \ldots, r_{0, T}^{j}\right)^{\prime}\right] \geq E\left(R^{d}\right)+\theta g_{E}^{R}, \\
\operatorname{Var}\left[\sum_{j=1}^{n} \lambda_{j}\left(r_{0,1}^{j}, r_{0,2}^{j}, \ldots, r_{0, T}^{j}\right)^{\prime}\right] \leq \operatorname{Var}\left(R^{d}\right)-\theta g_{V}^{R}, \\
\sum_{j=1}^{n} \lambda_{j}=1, \lambda_{j} \geq 0, j=1,2, \ldots, n .
\end{array}\right.
\end{aligned}
$$

It is not difficult to find that Model (2.5) is an output-oriented diversification DEA model. To illustrate the difference between the proposed DEA model and the corresponding DEA model based on the traditional inputoutput assumption (i.e., the variance of portfolio return is regarded as an input indicator and the expected return is regarded as an output indicator), we also provide the following output-oriented diversification DEA model as the comparison.

$$
\begin{aligned}
& \widetilde{\theta}_{1}^{d}=\max \theta \\
& \text { s.t. }\left\{\begin{array}{l}
E\left[\sum_{j=1}^{n} \lambda_{j}\left(r_{0,1}^{j}, r_{0,2}^{j}, \ldots, r_{0, T}^{j}\right)^{\prime}\right] \geq E\left(R^{d}\right)+\theta g_{E}^{R}, \\
\operatorname{Var}\left[\sum_{j=1}^{n} \lambda_{j}\left(r_{0,1}^{j}, r_{0,2}^{j}, \ldots, r_{0, T}^{j}\right)^{\prime}\right] \leq \operatorname{Var}\left(R^{d}\right), \\
\sum_{j=1}^{n} \lambda_{j}=1, \lambda_{j} \geq 0, j=1,2, \ldots, n .
\end{array}\right.
\end{aligned}
$$

Although Models (2.5) and (2.6) are both output-oriented DEA models, Model (2.5) assumes that the variance and expected return are both outputs, which is more coincident with the real investment process compared to Model (2.6).

From Model (2.5), we find that if the optimal value of this model is equal to 0 , the portfolio being evaluated is called as an efficient portfolio under the multi-horizon framework. In this case, the portfolio efficiency can be defined as $\hat{\theta}_{1}^{d}=1-\theta_{1}^{d}$. It is not difficult to find that Model (2.5) has considered the comprehensive performance of portfolios in different time horizons. For convenience, we further assume that the optimal solution of Model $(2.5)$ is $\left(\theta^{*}, \lambda_{1}^{*}, \ldots, \lambda_{n}^{*}\right)^{\prime}$. Then, Model (2.5) can not only provide a comprehensive evaluation but also provide an improvement benchmark for an inefficient portfolio $\left(i . e ., \hat{\theta}_{1}^{d}<1\right)$, and that the benchmark can be realized by using the improvement strategy $\lambda^{*}=\left(\lambda_{1}^{*}, \ldots, \lambda_{n}^{*}\right)^{\prime}$. That is to say, decision-makers can improve the mean and variance of an inefficient portfolio to an efficient state in the different time horizons by applying $\lambda^{*}=$ $\left(\lambda_{1}^{*}, \ldots, \lambda_{n}^{*}\right)^{\prime}$. To further illustrate the advantages of the multi-horizon Model (2.5), we will show the difference between Model (2.5) and the single-horizon model. Under the single-horizon perspective, portfolio managers only consider the performance of portfolios at a given time horizon $t$, where $t=1,2, \ldots, T$. Then, the following stochastic output possibility set of portfolios can be constructed similarly.

$$
\Phi_{1}^{t}=\left\{r_{0, t} \mid r_{0, t}=\sum_{j=1}^{n} \mu_{t}^{j} r_{0, t}^{j}, \sum_{j=1}^{n} \mu_{t}^{j}=1, \mu_{t}^{j} \geq 0, j=1,2, \ldots, n\right\} .
$$


Based on Set (2.7), under the mean-variance criterion, we can also construct the following deterministic output possibility set from the single-horizon perspective.

$$
\operatorname{PPS}_{1}^{t}=\left\{\begin{array}{l|l}
\left(E\left(r_{0, t}\right), \operatorname{Var}\left(r_{0, t}\right)\right) & \begin{array}{l}
E\left(\sum_{j=1}^{n} \mu_{t}^{j} r_{0, t}^{j}\right) \geq E\left(r_{0, t}\right), \\
\operatorname{Var}\left(\sum_{j=1}^{n} \mu_{t}^{j} r_{0, t}^{j}\right) \leq E\left(r_{0, t}\right), \\
\sum_{j=1}^{n} \mu_{t}^{j}=1, \mu_{t}^{j} \geq 0, j=1,2, \ldots, n .
\end{array}
\end{array}\right\}
$$

Based on Set (2.8), under a given projection direction $\left(g_{E}^{r_{t}},-g_{V}^{r_{t}}\right)^{\prime}$, we assume that $\left(E\left(r_{0, t}^{d}\right)+\theta_{t} g_{E}^{r_{t}}, \operatorname{Var}\left(r_{0, t}^{d}\right)-\theta_{t} g_{V}^{r_{t}}\right) \in \mathrm{PPS}_{1}^{t}$, then the following single-horizon diversification DEA model can be obtained: $\theta_{1, t}^{d}=\max _{\theta_{t}}\left\{\theta_{t} \mid\left(E\left(r_{0, t}^{d}\right)+\theta g_{E}^{r_{t}}\right.\right.$, $\left.\left.\operatorname{Var}\left(r_{0, t}^{d}\right)-\theta g_{V}^{r_{t}}\right) \in \mathrm{PPS}_{1}^{t}\right\}$. Specifically, it can be expressed as:

$$
\begin{aligned}
& \theta_{1, t}^{d}=\max \theta_{t} \\
& \text { s.t. }\left\{\begin{array}{l}
E\left(\sum_{j=1}^{n} \mu_{t}^{j} r_{0, t}^{j}\right) \geq E\left(r_{0, t}\right)+\theta_{t} g_{E}^{r_{t}}, \\
\operatorname{Var}\left(\sum_{j=1}^{n} \mu_{t}^{j} r_{0, t}^{j}\right) \leq E\left(r_{0, t}\right)-\theta_{t} g_{V}^{r_{t}}, \\
\sum_{j=1}^{n} \mu_{t}^{j}=1, \mu_{t}^{j} \geq 0, j=1,2, \ldots, n .
\end{array}\right.
\end{aligned}
$$

According to Model (2.9), if $\theta_{1, t}^{d}=0$, the portfolio being evaluated is called as an efficient portfolio in the $t$-th time horizon, and then the portfolio efficiency can be recorded as $\hat{\theta}_{1, t}^{d}=1-\theta_{1, t}^{d}$. Similarly, let the optimal solution of Model (2.9) be $\left(\theta_{t^{*}}, \mu_{t^{*}}^{1}, \ldots, \mu_{t^{*}}^{n}\right)^{\prime}$. In this case, using the improvement strategy $\mu_{t^{*}}=\left(\mu_{t^{*}}^{1}, \ldots, \mu_{t^{*}}^{n}\right)^{\prime}$, decision-makers not only can contract the variance of portfolio return, but also can expand the expected return. However, decision-markers are limited to improving the mean and variance of an inefficient portfolio to a locally efficient state in the $t$-th time horizon. To further analyze the difference between the improvement strategies provided by Models (2.5) and (2.9), we might well as assume $T=3$, and then we can obtain the improvement strategies (i.e., $\lambda^{*}, \mu_{1^{*}}, \mu_{2^{*}}$ and $\mu_{3^{*}}$ ) provided by Models (2.5) and (2.9). The details are shown in Figure 2.

Figure 2a shows the improvement strategy $\lambda^{*}$ provided by Model (2.5), and this improvement strategy combines the performance of the portfolio being evaluated in the different time horizons. In other words, portfolio managers can use this strategy to uniformly improve the expectation and variance of the portfolio return in each time horizon. On the other hand, Figure $2 \mathrm{~b}$ shows the schematic diagram of the improvement strategy provided by Model (2.9). It is not difficult to find that Model (2.9) can only provide an improvement strategy $\mu_{t^{*}}(t=1,2,3)$ for the portfolio being evaluated at a given time horizon $t$. Under the single-horizon framework, if portfolio managers just concern about the performance of portfolios at a given time horizon, then they will choose a strategy from the above three improvement strategies (i.e., $\mu_{1^{*}}, \mu_{2^{*}}$ and $\mu_{3^{*}}$ ). For example, if portfolio managers only care about the portfolio performance in the first time horizon, then they will adopt the strategy $\mu_{1^{*}}$ to improve the portfolio performance. However, the strategy $\mu_{1^{*}}$ can only ensure that the portfolio being evaluated will be improved in the time horizon 1, but it cannot take into account the performance in other two time horizons. Similar to the strategy $\mu_{1^{*}}$, the other two improvement strategies (i.e., $\mu_{2^{*}}$ and $\left.\mu_{3^{*}}\right)$ also have the same dilemma. 


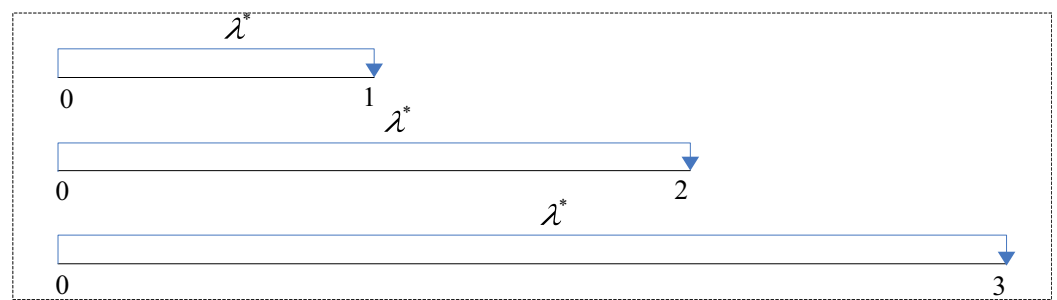

(a)

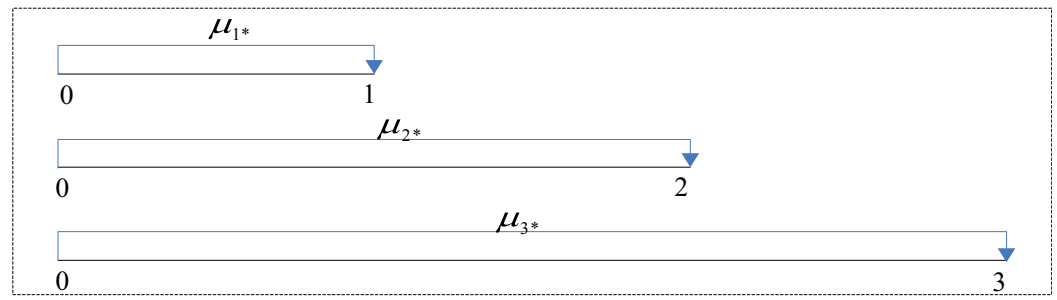

(b)

FiguRE 2. The difference between the improvement strategies from different DEA models.

\subsection{Multi-horizon diversification DEA model considering social responsibility}

In this section, assuming that portfolio managers not only concern about the performance of portfolio returns, but also consider the social responsibility performance of portfolios. According to the input-output process shown in Figure 1b, using the traditional convexity assumption, then we can construct the following stochastic output possibility set from the multi-horizon perspective.

$$
\Phi_{2}=\left\{\begin{array}{l|l}
R, S) & \begin{array}{l}
R=\sum_{j=1}^{n} \lambda_{j}\left(r_{0,1}^{j}, r_{0,2}^{j}, \ldots, r_{0, T}^{j}\right)^{\prime}, \\
S=\sum_{j=1}^{n} \lambda_{j}\left(s_{0,1}^{j}, s_{0,2}^{j}, \ldots, s_{0, T}^{j}\right)^{\prime} \\
\sum_{j=1}^{n} \lambda_{j}=1, \lambda_{j} \geq 0, j=1,2, \ldots, n .
\end{array}
\end{array}\right\}
$$

Similar to Section 2.1, we use the expectation and variance measures to estimate the stochastic constraints in Set (2.10). We further assume that the expectations and variances of the portfolio return and social responsibility indicator satisfy the strong free disposability assumption, and then the deterministic output possibility set of portfolios from the multi-horizon perspective can be constructed as follows. 


$$
\mathrm{PPS}_{2}=\left\{\begin{array}{l|l}
(E(R), \operatorname{Var}(R), E(S), \operatorname{Var}(S)) & \begin{array}{l}
E(R) \leq E\left[\sum_{j=1}^{n} \lambda_{j}\left(r_{0,1}^{j}, r_{0,2}^{j}, \ldots, r_{0, T}^{j}\right)^{\prime}\right], \\
\operatorname{Var}(R) \geq \operatorname{Var}\left[\sum_{j=1}^{n} \lambda_{j}\left(r_{0,1}^{j}, r_{0,2}^{j}, \ldots, r_{0, T}^{j}\right)^{\prime}\right], \\
E(S) \leq E\left[\sum_{j=1}^{n} \lambda_{j}\left(s_{0,1}^{j}, s_{0,2}^{j}, \ldots, s_{0, T}^{j}\right)^{\prime}\right], \\
\operatorname{Var}(S) \geq \operatorname{Var}\left[\sum_{j=1}^{n} \lambda_{j}\left(s_{0,1}^{j}, s_{0,2}^{j}, \ldots, s_{0, T}^{j}\right)^{\prime}\right], \\
\sum_{j=1}^{n} \lambda_{j}=1, \lambda_{j} \geq 0, j=1,2, \ldots, n .
\end{array}
\end{array}\right\}
$$

For the $d$-th portfolio being evaluated, we assume that portfolio managers are willing to measure the portfolio efficiency at a given level of social responsibility. That is to say, portfolio managers are more concerned with the performance of portfolio returns compared to the social responsibility performance of portfolios. At this time, for a given projection direction $\left(g_{E}^{R},-g_{V}^{R}, 0_{T \times 1}, 0_{T \times 1}\right)^{\prime}$ (note that the specific forms of $g_{E}^{R}$ and $g_{V}^{R}$ are shown in Section 2.1, and $0_{T \times 1}=\underbrace{(0,0, \ldots, 0)^{\prime}}_{T})$, we can construct the following multi-horizon diversification DEA model under the financial orientation.

$$
\begin{aligned}
& \theta_{2}^{d}=\max \theta \\
& \text { s.t. }\left\{\begin{array}{l}
E\left[\sum_{j=1}^{n} \lambda_{j}\left(r_{0,1}^{j}, r_{0,2}^{j}, \ldots, r_{0, T}^{j}\right)^{\prime}\right] \geq E\left(R^{d}\right)+\theta g_{E}^{R}, \\
\operatorname{Var}\left[\sum_{j=1}^{n} \lambda_{j}\left(r_{0,1}^{j}, r_{0,2}^{j}, \ldots, r_{0, T}^{j}\right)^{\prime}\right] \leq \operatorname{Var}\left(R^{d}\right)-\theta g_{V}^{R}, \\
E\left[\sum_{j=1}^{n} \lambda_{j}\left(s_{0,1}^{j}, s_{0,2}^{j}, \ldots, s_{0, T}^{j}\right)^{\prime}\right] \geq E\left(S^{d}\right), \\
\operatorname{Var}\left[\sum_{j=1}^{n} \lambda_{j}\left(s_{0,1}^{j}, s_{0,2}^{j}, \ldots, s_{0, T}^{j}\right)^{\prime}\right] \leq \operatorname{Var}\left(S^{d}\right), \\
\sum_{j=1}^{n} \lambda_{j}=1, \lambda_{j} \geq 0, j=1,2, \ldots, n .
\end{array}\right.
\end{aligned}
$$

Similarly, we assume that portfolio managers want to estimate the portfolio efficiency at a given financial level. In this case, portfolio managers are more inclined to the social responsibility performance of portfolios rather than their financial performance. Under a given projection direction $\left(0_{T \times 1}, 0_{T \times 1}, g_{E}^{S},-g_{V}^{S}\right)^{\prime}$, where $g_{E}^{S}=$ $\left(g_{E}^{s_{1}}, g_{E}^{s_{2}}, \ldots, g_{E}^{s_{T}}\right)^{\prime}$ and $g_{V}^{S}=\left(g_{V}^{s_{1}}, g_{V}^{s_{2}}, \ldots, g_{V}^{s_{T}}\right)^{\prime}$, the following multi-horizon diversification DEA model under the social responsibility orientation can be constructed. 


$$
\begin{aligned}
& \theta_{3}^{d}=\max \eta \\
& \text { s.t. }\left\{\begin{array}{l}
E\left[\sum_{j=1}^{n} \lambda_{j}\left(r_{0,1}^{j}, r_{0,2}^{j}, \ldots, r_{0, T}^{j}\right)^{\prime}\right] \geq E\left(R^{d}\right), \\
\operatorname{Var}\left[\sum_{j=1}^{n} \lambda_{j}\left(r_{0,1}^{j}, r_{0,2}^{j}, \ldots, r_{0, T}^{j}\right)^{\prime}\right] \leq \operatorname{Var}\left(R^{d}\right), \\
E\left[\sum_{j=1}^{n} \lambda_{j}\left(s_{0,1}^{j}, s_{0,2}^{j}, \ldots, s_{0, T}^{j}\right)^{\prime}\right] \geq E\left(S^{d}\right)+\eta g_{E}^{S}, \\
\operatorname{Var}\left[\sum_{j=1}^{n} \lambda_{j}\left(s_{0,1}^{j}, s_{0,2}^{j}, \ldots, s_{0, T}^{j}\right)^{\prime}\right] \leq \operatorname{Var}\left(S^{d}\right)-\eta g_{V}^{S}, \\
\sum_{j=1}^{n} \lambda_{j}=1, \lambda_{j} \geq 0, j=1,2, \ldots, n .
\end{array}\right.
\end{aligned}
$$

Furthermore, we assume that portfolio managers will estimate the portfolio efficiency by measuring both the financial and social responsibility performance. Under a given projection direction $\left(g_{E}^{R},-g_{V}^{R}, g_{E}^{S},-g_{V}^{S}\right)^{\prime}$, then we can construct the following non-oriented multi-horizon diversification DEA model.

$$
\begin{aligned}
& \theta_{4}^{d}=\max w \theta+(1-w) \eta \\
& \text { s.t. }\left\{\begin{array}{l}
E\left[\sum_{j=1}^{n} \lambda_{j}\left(r_{0,1}^{j}, r_{0,2}^{j}, \ldots, r_{0, T}^{j}\right)^{\prime}\right] \geq E\left(R^{d}\right)+\theta g_{E}^{R}, \\
\operatorname{Var}\left[\sum_{j=1}^{n} \lambda_{j}\left(r_{0,1}^{j}, r_{0,2}^{j}, \ldots, r_{0, T}^{j}\right)^{\prime}\right] \leq \operatorname{Var}\left(R^{d}\right)-\theta g_{V}^{R}, \\
E\left[\sum_{j=1}^{n} \lambda_{j}\left(s_{0,1}^{j}, s_{0,2}^{j}, \ldots, s_{0, T}^{j}\right)^{\prime}\right] \geq E\left(S^{d}\right)+\eta g_{E}^{S}, \\
\operatorname{Var}\left[\sum_{j=1}^{n} \lambda_{j}\left(s_{0,1}^{j}, s_{0,2}^{j}, \ldots, s_{0, T}^{j}\right)^{\prime}\right] \leq \operatorname{Var}\left(S^{d}\right)-\eta g_{V}^{S}, \\
\sum_{j=1}^{n} \lambda_{j}=1, \lambda_{j} \geq 0, j=1,2, \ldots, n .
\end{array}\right.
\end{aligned}
$$

Here, the weight coefficient $w$ satisfies the condition that $0 \leq w \leq 1$.

Models (2.12)-(2.14) indicate that, if the optimal value meets that $\theta_{k}^{d}=0(k=2,3,4)$, the portfolio being evaluated is called as an efficient portfolio, and its portfolio efficiency can be expressed as $\hat{\theta}_{k}^{d}=1-\theta_{k}^{d}(k=2,3,4)$.

Similar to Section 2.1, we also assume that portfolio managers only consider the performance of portfolios in a given time horizon $t(t=1,2, \ldots, T)$. In this situation, then we can construct the following stochastic output possibility set of portfolios with consideration of the portfolio return and the social responsibility indicator.

$$
\Phi_{2}^{t}=\left\{\begin{array}{l|l}
\left(r_{0, t}, s_{0, t}\right) & \begin{array}{l}
r_{0, t}=\sum_{j=1}^{n} \mu_{t}^{j} r_{0, t}^{j}, s_{0, t}=\sum_{j=1}^{n} \mu_{t}^{j} s_{0, t}^{j}, \\
\sum_{j=1}^{n} \mu_{t}^{j}=1, \mu_{t}^{j} \geq 0, j=1,2, \ldots, n .
\end{array}
\end{array}\right\}
$$


Based on Set (2.15), the deterministic output possibility set within the mean-variance framework can be expressed as follows.

$$
\operatorname{PPS}_{2}^{t}=\left\{\begin{array}{l|l}
\left(E\left(r_{0, t}\right), \operatorname{Var}\left(r_{0, t}\right), E\left(s_{0, t}\right), \operatorname{Var}\left(s_{0, t}\right)\right) & \begin{array}{l}
E\left(\sum_{j=1}^{n} \mu_{t}^{j} r_{0, t}^{j}\right) \geq E\left(r_{0, t}\right), \\
\operatorname{Var}\left(\sum_{j=1}^{n} \mu_{t}^{j} r_{0, t}^{j}\right) \leq E\left(r_{0, t}\right), \\
E\left(\sum_{j=1}^{n} \mu_{t}^{j} s_{0, t}^{j}\right) \geq E\left(s_{0, t}\right), \\
\operatorname{Var}\left(\sum_{j=1}^{n} \mu_{t}^{j} s_{0, t}^{j}\right) \leq E\left(s_{0, t}\right), \\
\sum_{j=1}^{n} \mu_{t}^{j}=1, \mu_{t}^{j} \geq 0, j=1,2, \ldots, n .
\end{array}
\end{array}\right\}
$$

Under the framework of Set (2.16), we can propose the following single-horizon diversification DEA models in different orientations.

(i) Single-horizon model under the financial orientation:

$$
\text { s.t. }\left\{\begin{array}{l}
\theta_{2, t}^{d}=\max \theta_{t} \\
\operatorname{Var}\left(\sum_{j=1}^{n} \mu_{t}^{j} r_{0, t}^{j}\right) \geq E\left(r_{0, t}\right)+\theta_{t} g_{E}^{r_{t}}, \\
E\left(\sum_{j=1}^{n} \mu_{t}^{j} s_{0, t}^{j}\right) \leq E\left(r_{0, t}\right)-\theta_{t} g_{V}^{r_{t}}, \\
\operatorname{Var}\left(\sum_{j=1}^{n} \mu_{t}^{j} s_{0, t}^{j}\right) \leq E\left(s_{0, t}\right), \\
\sum_{j=1}^{n} \mu_{t}^{j}=1, \mu_{t}^{j} \geq 0, j=1,2, \ldots, n .
\end{array}\right.
$$


(ii) Single-horizon model under the social responsibility orientation:

$$
\text { s.t. }\left\{\begin{array}{l}
\theta_{3, t}^{d}=\max \eta_{t} \\
E\left(\sum_{j=1}^{n} \mu_{t}^{j} r_{0, t}^{j}\right) \geq E\left(r_{0, t}\right), \\
\operatorname{Var}\left(\sum_{j=1}^{n} \mu_{t}^{j} r_{0, t}^{j}\right) \leq E\left(r_{0, t}\right), \\
E\left(\sum_{j=1}^{n} \mu_{t}^{j} s_{0, t}^{j}\right) \geq E\left(s_{0, t}\right)+\eta_{t} g_{E}^{s_{t}}, \\
\operatorname{Var}\left(\sum_{j=1}^{n} \mu_{t}^{j} s_{0, t}^{j}\right) \leq E\left(s_{0, t}\right)-\eta_{t} g_{V}^{s_{t}}, \\
\sum_{j=1}^{n} \mu_{t}^{j}=1, \mu_{t}^{j} \geq 0, j=1,2, \ldots, n .
\end{array}\right.
$$

(iii) Single-horizon model under the non-orientation:

$$
\text { s.t. }\left\{\begin{array}{l}
\theta_{4, t}^{d}=\max w \theta_{t}+(1-w) \eta_{t} \\
E\left(\sum_{j=1}^{n} \mu_{t}^{j} r_{0, t}^{j}\right) \geq E\left(r_{0, t}\right)+\theta_{t} g_{E}^{r_{t}}, \\
\operatorname{Var}\left(\sum_{j=1}^{n} \mu_{t}^{j} r_{0, t}^{j}\right) \leq E\left(r_{0, t}\right)-\theta_{t} g_{V}^{r_{t}}, \\
E\left(\sum_{j=1}^{n} \mu_{t}^{j} s_{0, t}^{j}\right) \geq E\left(s_{0, t}\right)+\eta_{t} g_{E}^{s_{t}}, \\
\operatorname{Var}\left(\sum_{j=1}^{n} \mu_{t}^{j} s_{0, t}^{j}\right) \leq E\left(s_{0, t}\right)-\eta_{t} g_{V}^{s_{t}}, \\
\sum_{j=1}^{n} \mu_{t}^{j}=1, \mu_{t}^{j} \geq 0, j=1,2, \ldots, n .
\end{array}\right.
$$

As shown in Models (2.17)-(2.19), for a given time horizon $t$, the portfolio being evaluated is called as an efficient portfolio when the optimal value satisfies that $\theta_{k, t}^{d}=0(k=2,3,4)$. What is more, the portfolio efficiency can be expressed as $\hat{\theta}_{k, t}^{d}=1-\theta_{k, t}^{d}(k=2,3,4)$.

\section{EMPIRICAL ANALYSIS}

To verify the effectiveness of the proposed DEA models, we use the component stocks of China ESG100 index as the test sample, and the data ranging from January 1, 2010 to December 31, 2018, where the asset return is weekly data and the social responsibility score is annual data. Due to the lack of the return data of component stocks, we only selected 20 component stocks without missing data as the evaluation objects. The stock codes are as follows: 000001, 000002, 000568, 000651, 000776, 000858, 000895, 600000, 600066, 600068, 600089, 600104, 600111, 600115, 600188, 600196, 600660, 600690, 600741, and 600893. Based on the 9-year data of the return rate and social responsibility score, we divide them into three time horizons to estimate the 
TABLE 1. The calculation criteria of social responsibility scores of listed companies.

\begin{tabular}{|c|c|c|}
\hline First level indicators & Second level indicators & Third level indicators \\
\hline \multirow{5}{*}{$\begin{array}{l}\text { Social responsibility score (the total } \\
\text { score is } 100 \text { ) }\end{array}$} & $\begin{array}{l}\text { Shareholder responsibility score } \\
(30 \%)\end{array}$ & $\begin{array}{l}\text { Debt service score }(3 \%) \\
\text { Return score }(8 \%) \\
\text { Letter batch score }(5 \%) \\
\text { Innovation score }(4 \%)\end{array}$ \\
\hline & $\begin{array}{lll}\text { Employee } & \text { responsibility } & \text { score } \\
(15 \%) & \end{array}$ & $\begin{array}{l}\text { Performance score }(5 \%) \\
\text { Security score }(5 \%) \\
\text { Caring for employees score }(5 \%)\end{array}$ \\
\hline & $\begin{array}{l}\text { Supplier, customer and consumer } \\
\text { responsibility score }(15 \%)\end{array}$ & $\begin{array}{l}\text { Product quality score }(7 \%) \\
\text { After-sales service score }(3 \%) \\
\text { Integrity and reciprocity score }(5 \%)\end{array}$ \\
\hline & $\begin{array}{l}\text { Environmental responsibility score } \\
(20 \%)\end{array}$ & $\begin{array}{l}\text { Environmental management score } \\
(20 \%)\end{array}$ \\
\hline & Social contribution score $(20 \%)$ & Contribution score $(20 \%)$ \\
\hline
\end{tabular}

efficiency of the assets above. Specifically, 2010-2012 is regarded as the first time horizon (i.e., $t=1$ ), 20102015 is regarded as the second time horizon (i.e., $t=2$ ), and 2010-2018 is treated as the third time horizon (i.e., $t=3$ ). Here, the return data is downloaded from RESSET database (http://db.resset.com/), and the social responsibility scores of the listed companies are downloaded from Hexun database (http://stockdata. stock.hexun.com/zrbg/Plate.aspx). As far as we know, social responsibility is a multi-dimensional concept that involves identifying a number of criteria and the corresponding weights for evaluating the financial assets. Hexun database provides not only the total social responsibility scores of listed companies, but also their subscores per evaluation dimension and their weights in the total score calculation (note that the specific weight settings can be found in http://stock.hexun.com/2013/gsshzr/index.html). And these data have been widely used in empirical analysis by many scholars, such as Han et al. [19], Zhong et al. [33], and Chen et al. [14]. To be specific, the default calculation criteria of social responsibility scores of listed companies in Hexun database are shown in Table 1.

In addition to this, we assume that the directions (i.e., $g_{E}^{r_{t}}, g_{V}^{r_{t}}, g_{E}^{s_{t}}$ and $g_{V}^{s_{t}}$ ) shown in Section 2 satisfy the following conditions: $g_{E}^{r_{t}}=\max _{j}\left(E\left(r_{j, t}\right)\right)-\min _{j}\left(E\left(r_{j, t}\right)\right), g_{V}^{r_{t}}=\max _{j}\left(\operatorname{Var}\left(r_{j, t}\right)\right)-\min _{j}\left(\operatorname{Var}\left(r_{j, t}\right)\right), g_{E}^{s_{t}}=$ $\max _{j}\left(E\left(s_{j, t}\right)\right)-\min _{j}\left(E\left(s_{j, t}\right)\right)$ and $g_{V}^{s_{t}}=\max _{j}\left(\operatorname{Var}\left(s_{j, t}\right)\right)-\min _{j}\left(\operatorname{Var}\left(s_{j, t}\right)\right)$. Briefly speaking, our empirical analysis has the following twofold purposes: (i) To investigate the difference between the multi-horizon models and the single-horizon models when the portfolio managers consider and do not consider the social responsibility scores. (ii) To shown the impact of the social responsibility score on the portfolio efficiency and its ranking. For the above two purposes, we can obtain the empirical results such as those in Sections 3.1 and 3.2.

\subsection{Portfolio efficiency analysis without considering the social responsibility}

When the portfolio managers only consider the performance of the portfolio returns, we can obtain the corresponding portfolio efficiency and its ranking under the framework of Models (2.5) and (2.9). The detailed results are shown in Table 2.

Compared with Models (2.9), (2.5) comprehensively considers the performance of portfolios in each time horizon. As shown in Table 1, there is a certain difference between the portfolio efficiency/ranking obtained by Model (2.5) and that obtained by Model (2.9). To further discuss the difference between the above two 
TABle 2. Portfolio efficiency and its ranking without considering social responsibility.

\begin{tabular}{lllllllll}
\hline \hline \multirow{2}{*}{ Portfolio } & \multicolumn{2}{c}{ Model (2.5) } & \multicolumn{7}{c}{ Model (2.9) } \\
\cline { 2 - 8 } & \multicolumn{2}{c}{} & \multicolumn{2}{c}{$t=1$} & \multicolumn{2}{c}{$t=2$} & \multicolumn{2}{c}{$t=3$} \\
\cline { 2 - 8 } & Efficiency & Ranking & Efficiency & Ranking & Efficiency & Ranking & Efficiency & Ranking \\
\hline 000001 & 0.5573 & 17 & 0.5573 & 18 & 0.3943 & 18 & 0.1476 & 20 \\
000002 & 1.0000 & 1 & 0.7170 & 10 & 0.9318 & 3 & 0.9154 & 2 \\
000568 & 0.8460 & 5 & 0.7459 & 7 & 0.6433 & 10 & 0.7832 & 5 \\
000651 & 1.0000 & 1 & 0.7419 & 9 & 0.8437 & 4 & 1.0000 & 1 \\
000776 & 0.5439 & 18 & 0.5005 & 20 & 0.1000 & 20 & 0.3828 & 16 \\
000858 & 0.7747 & 10 & 0.7035 & 12 & 0.7695 & 7 & 0.6045 & 9 \\
000895 & 0.9496 & 2 & 0.7546 & 6 & 0.9384 & 2 & 0.7760 & 7 \\
600000 & 0.7449 & 11 & 0.7449 & 8 & 0.6528 & 9 & 0.2089 & 18 \\
600066 & 0.9345 & 3 & 0.8855 & 2 & 0.8294 & 5 & 0.8354 & 4 \\
600068 & 0.7181 & 14 & 0.6829 & 13 & 0.5800 & 14 & 0.4982 & 12 \\
600089 & 0.9030 & 4 & 0.5456 & 19 & 0.5538 & 15 & 0.9030 & 3 \\
600104 & 0.8284 & 7 & 0.8278 & 3 & 0.5967 & 12 & 0.4244 & 13 \\
600111 & 0.7228 & 12 & 0.6817 & 14 & 0.3937 & 19 & 0.5600 & 10 \\
600115 & 0.8195 & 8 & 0.8195 & 4 & 0.5230 & 16 & 0.1727 & 19 \\
600188 & 0.7819 & 9 & 0.7043 & 11 & 0.7819 & 6 & 0.5534 & 11 \\
600196 & 0.7223 & 13 & 0.5860 & 16 & 0.6234 & 11 & 0.6445 & 8 \\
600660 & 1.0000 & 1 & 1.0000 & 1 & 1.0000 & 1 & 0.7770 & 6 \\
600690 & 0.6965 & 15 & 0.6046 & 15 & 0.5881 & 13 & 0.3891 & 15 \\
600741 & 0.8348 & 6 & 0.8188 & 5 & 0.6974 & 8 & 0.4068 & 14 \\
600893 & 0.6065 & 16 & 0.5800 & 17 & 0.4432 & 17 & 0.2339 & 17 \\
\hline
\end{tabular}

TABLE 3. The efficiencies and rankings correlation coefficients of portfolios.

\begin{tabular}{lllll}
\hline \hline \multicolumn{5}{c}{ Panel A: The correlation coefficients of the portfolio efficiencies } \\
\hline Correlation coefficient & Model (2.5) & Model $(2.9)(t=1)$ & Model $(2.9)(t=2)$ & Model $(2.9)(t=3)$ \\
Model (2.5) & 1.0000 & & & \\
Model (2.9) $(t=1)$ & 0.6901 & 1.0000 & 1.0000 & \\
Model (2.9) $(t=2)$ & 0.8489 & 0.6820 & 0.6174 & 1.0000 \\
Model (2.9) $(t=3)$ & 0.7765 & 0.2443 & Model $(2.9)(t=2)$ & Model $(2.9)(t=3)$ \\
\hline \multicolumn{5}{c}{ Panel B: The correlation coefficients of the portfolio rankings } \\
\hline Correlation coefficient & Model (2.5) & Model $(2.9)(t=1)$ & \\
Model (2.5) & 1.0000 & & & \\
Model (2.9) $(t=1)$ & 0.6938 & 1.0000 & 1.0000 & 1.0000 \\
Model (2.9) $(t=2)$ & 0.7876 & 0.6511 & 0.6211 & \\
Model $(2.9)(t=3)$ & 0.7610 & 0.2226 &
\end{tabular}

diversification DEA models, we will provide the correlation between the portfolio efficiencies/rankings of Models (2.5) and (2.9), and the detailed results are shown in Table 3.

From Panel A in Table 3, we find that the correlation coefficient between the portfolio efficiency obtained by Model (2.5) and that obtained by Model (2.9) in the first, second or third time horizons is not very high. That is to say, there is a certain difference between Models (2.5) and (2.9) in the different time horizons. Especially, this difference is more obvious between Models (2.5) and (2.9) in the first time horizon. In addition to this, we further discuss the difference between the rankings obtained from the above diversification DEA models. As can be seen from Panel B in Table 3, the ranking obtained by Model (2.5) is also different from that obtained 
by Model (2.9). In particular, the ranking difference is also more significant between Models (2.5) and (2.9) in the first time horizon, which is consistent with the conclusion in Panel A. Combining the results of Panels A and $\mathrm{B}$ in Table 3, we find that if portfolio managers only focus on the performance of portfolios in a given time horizon, this short-sighted management strategy often leads to an unfair evaluation of portfolios. Apparently, the results in Table 3 further verify the rationality of the multi-horizon diversification DEA model proposed in this paper.

Tables 2 and 3 have discussed the difference between the multi-horizon model and the single-horizon model in terms of the portfolio efficiency and its ranking. In the following, we will investigate the improvement of the expectation and variance of the portfolio return by using the improvement strategies provided by Models (2.5) and (2.9) (i.e., $\lambda^{*}, \mu_{1^{*}}, \mu_{2^{*}}$ and $\mu_{3^{*}}$ ). That is, to discuss the amount by which the expected return can be increased and that the variance of the portfolio return can be reduced. Because the multi-horizon model considers a comprehensive performance of portfolios, therefore, it can provide an improvement strategy, and also this strategy has the consistency in each time horizon. However, the single-horizon models can only provide a local improvement strategy for the portfolio managers in a given time horizon, but they may not be able to take into account the performance of portfolios in other time horizons. In the following, we design the following comparison scheme to analyze the difference between Models (2.5) and (2.9).

(a) Under the framework of Model (2.5), for any portfolio being evaluated, using its improvement strategy $\lambda^{*}$, the improvements of the expectation and variance of the portfolio return in the different time horizons are as follows: $E\left(\sum_{j=1}^{n} \lambda_{j}^{*} r_{0, t}^{j}\right)-E\left(r_{0, t}\right)$ and $\operatorname{Var}\left(r_{0, t}\right)-\operatorname{Var}\left(\sum_{j=1}^{n} \lambda_{j}^{*} r_{0, t}^{j}\right)$, where $t=1,2,3$.

(b) Under the framework of Model (2.9), we assume that portfolio managers only concern about the performance of portfolios in a certain time horizon. To address this problem, we will analyze the improvement effect of expectation and variance in the following three cases.

Case (i) When portfolio managers only care about the performance of portfolios in the first time horizon, the improvement strategy $\mu_{1 *}$ will be used to adjust the expectations and variances of portfolio returns in the different time horizons, and then the corresponding improvements can be expressed as follows: $E\left(\sum_{j=1}^{n} \mu_{1^{*}}^{j} r_{0, t}^{j}\right)-E\left(r_{0, t}\right)$ and $\operatorname{Var}\left(r_{0, t}\right)-\operatorname{Var}\left(\sum_{j=1}^{n} \mu_{1^{*}}^{j} r_{0, t}^{j}\right)$, where $t=1,2,3$.

Case (ii) When portfolio managers only concern about the performance of portfolios in the second time horizon, the managers will use improvement strategy $\mu_{2^{*}}$ to adjust the expectations and variances in the different time horizons. Then, the corresponding improvements are as follows: $E\left(\sum_{j=1}^{n} \mu_{2^{*}}^{j} r_{0, t}^{j}\right)-E\left(r_{0, t}\right)$ and $\operatorname{Var}\left(r_{0, t}\right)-\operatorname{Var}\left(\sum_{j=1}^{n} \mu_{2 *}^{j} r_{0, t}^{j}\right)$, where $t=1,2,3$.

Case (iii) Similarly, when the portfolio managers only focus on the performance of portfolios in the third time horizon, the corresponding improvements of expectation and variance can be expressed as: $E\left(\sum_{j=1}^{n} \mu_{3^{*}}^{j} r_{0, t}^{j}\right)-E\left(r_{0, t}\right)$ and $\operatorname{Var}\left(r_{0, t}\right)-\operatorname{Var}\left(\sum_{j=1}^{n} \mu_{3^{*}}^{j} r_{0, t}^{j}\right)$, where $t=1,2,3$.

Based on the above comparison scheme, we can obtain the improvements of portfolios in the two dimensions of expectation and variance. The details are shown in Figures 3-5.

Figure 3 shows the improvement difference of expectation and variance in the first time horizon. It can be seen from Figure 3, under the framework of Model (2.5), for an inefficient portfolio, the expectation and variance of the portfolio return can be both improved by using the improvement strategy. However, for Model (2.9), the performance of different improvement strategies in the first period is quite different. The main findings are as follows.

(a) When portfolio managers adopt the scheme in Case (i), we find that the expectation and variance of the portfolio return in the first time horizon can be improved effectively, and also the improvement effect is even better than that of Model (2.5). The cause is that, Model (2.9) under Case (i) exactly focuses on the performance of portfolios in the first time horizon, i.e., the improvement strategy can only maximize the portfolio performance in the first period.

(b) When portfolio managers adopt the schemes in Cases (ii) and (iii), the results show that the improvement strategies $\mu_{2^{*}}$ and $\mu_{3^{*}}$ not only cannot guarantee that the expectation and variance of all ineffective portfolios are effectively improved in the first period, but also reduces the expected return of many portfolios. 


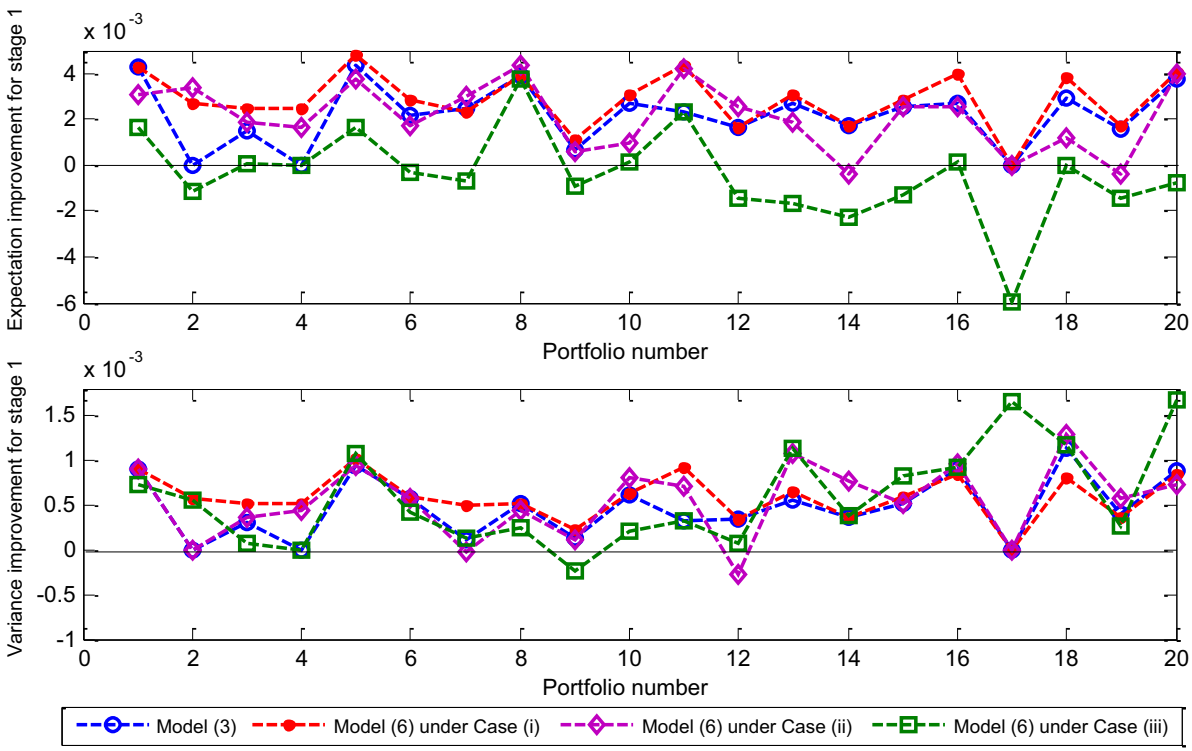

FiguRE 3. The improvements of expectation and variance in the first time horizon.
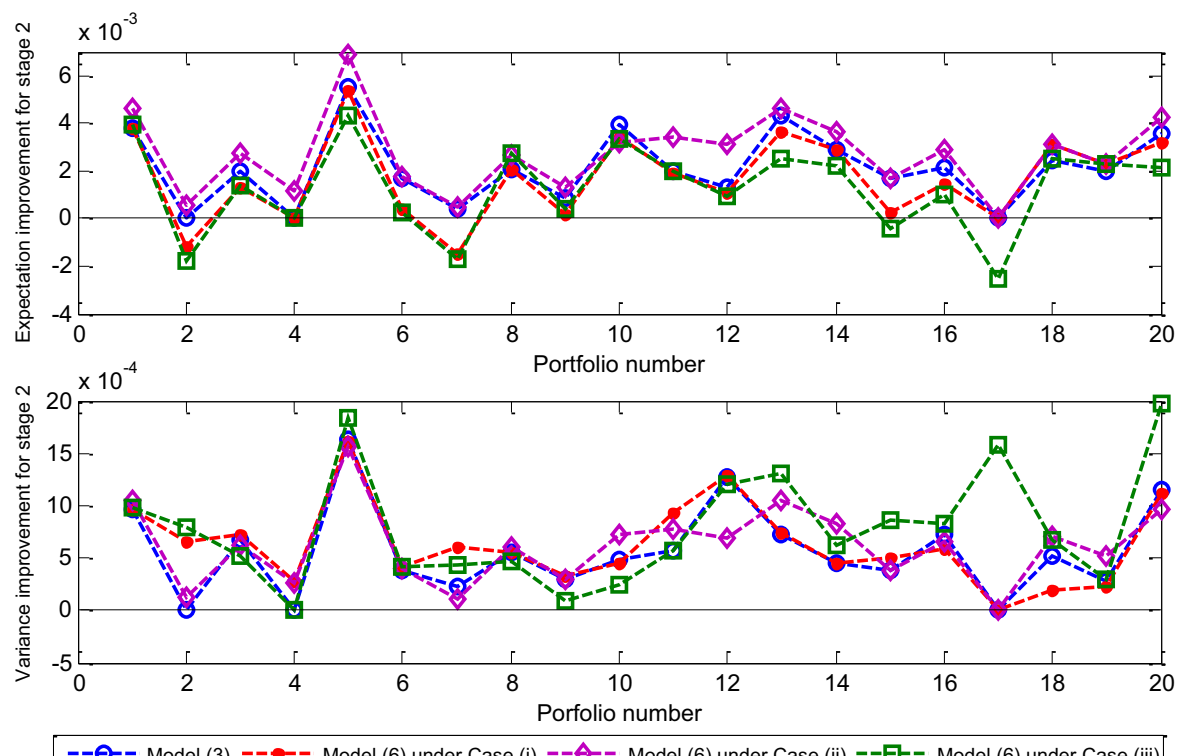

FigURE 4. The improvements of expectation and variance in the second time horizon.

Figure 4 shows the improvement effects of different improvement strategies on the expectation and variance of portfolio returns in the third time horizon. Similar to the conclusion in Figure 3, the improvement strategy obtained by Model (2.5) can also improve the expectation and variance of portfolio returns in the second time horizon. However, the improvement strategies derived from Cases (i) and (iii) only focus on the performance of portfolios in the first and third periods, this also makes the improvements of expectation and variance in the second time horizon are not ideal. 

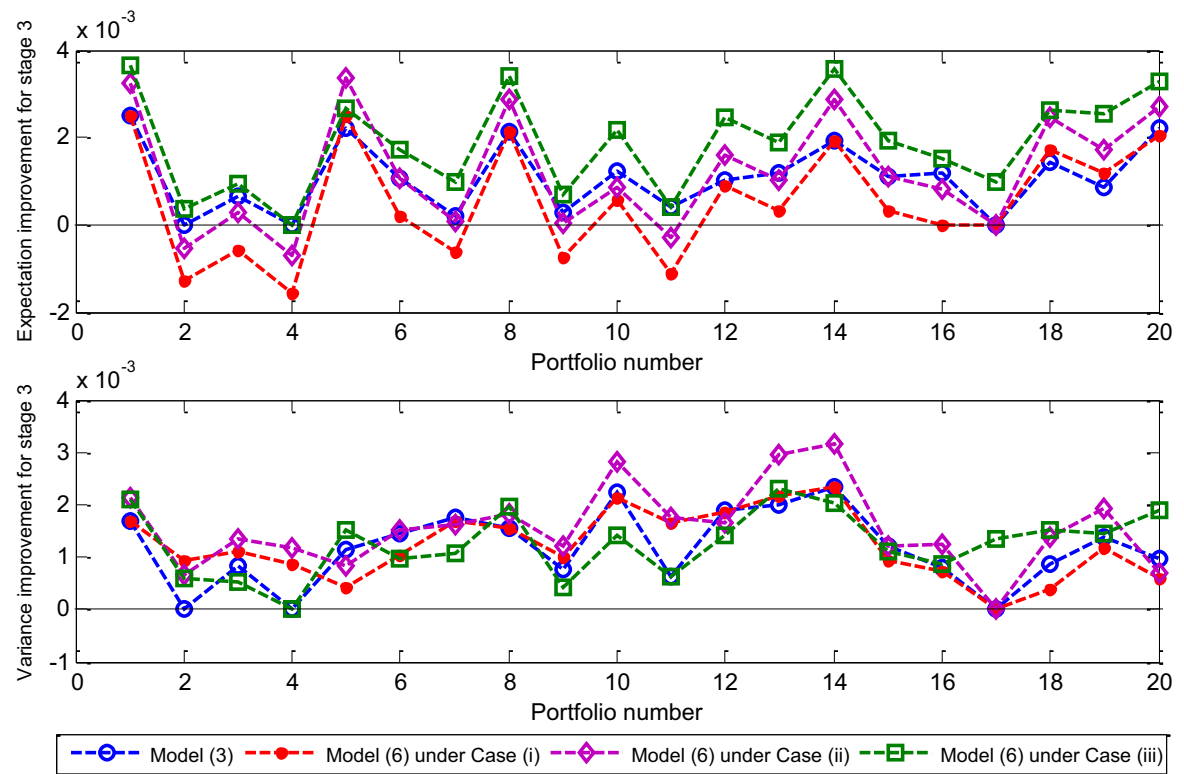

FigURE 5. The improvements of expectation and variance in the third time horizon.

Figure 5 shows the improvements of different improvement strategies on the expectation and variance of portfolio returns in the third time horizon. From Figure 5, we find that the improvement strategy obtained by Model (2.5) can also improve the expectation and variance of portfolio returns in the third time horizon. However, under the framework of Model (2.9), except for the improvement strategy in Case (iii), the improvement strategies in the other two cases (i.e., Cases (i) and (ii)) cannot guarantee that all inefficient portfolios are improved in the third time horizon.

Combining the results shown in Figures 3-5, we can conclude that Model (2.5) can provide a global improvement strategy to improve the expectation and variance of the inefficient portfolios in the different time horizons, while Model (2.9) can only provide a local improvement strategy within the single-horizon framework.

\subsection{Portfolio efficiency analysis considering the social responsibility}

When portfolio managers consider the performance of both portfolio return and social responsibility, the portfolio efficiency and its ranking can be derived by Models (2.12) and (2.17). The detailed results are shown in Tables $4-9$.

Models (2.12) and (2.17) are both the financial-oriented DEA models. At this time, portfolio managers will measure the portfolio efficiency at a given social responsibility level. The difference is that Model (2.12) can consider the performance of portfolios in different time horizons, while Model (2.17) only focuses on the portfolio performance within the single-horizon framework. As shown in Table 4, there is still a certain difference between the portfolio efficiencies/rankings of Models (2.12) and (2.17). Similarly, we also carry out a correlation test on the portfolio efficiency and its ranking. The results are shown in Table 5.

The results of Panel A in Table 5 show that, under the financial orientation, the correlation between the portfolio efficiency obtained by Model (2.12) and that obtained by Model (2.17) is not very high. This conclusion is also consistent with the conclusion in Table 3. What is more, by comparing the results in Tables 3 and 5 , we find that the social responsibility constraints can make the correlation coefficient between the multi-horizon model and single-horizon model became lower. In addition to this, Table 5 further indicates that the efficiency difference is more obvious between the multi-horizon model and the single-horizon model in the third period, 
TABLE 4. Portfolio efficiency and its ranking under the financial orientation.

\begin{tabular}{lllllllll}
\hline \hline \multirow{2}{*}{ Portfolio } & \multicolumn{2}{c}{ Model $(2.12)$} & \multicolumn{6}{c}{ Model $(2.17)$} \\
\cline { 2 - 8 } & \multicolumn{2}{c}{} & \multicolumn{2}{c}{$t=1$} & \multicolumn{2}{c}{$t=2$} & \multicolumn{2}{c}{$t=3$} \\
\cline { 2 - 8 } & Efficiency & Ranking & Efficiency & Ranking & Efficiency & Ranking & Efficiency & Ranking \\
\hline 000001 & 1.0000 & 1 & 0.5679 & 18 & 0.4056 & 16 & 0.1605 & 19 \\
000002 & 1.0000 & 1 & 1.0000 & 1 & 1.0000 & 1 & 1.0000 & 1 \\
000568 & 0.8800 & 5 & 0.7548 & 10 & 0.6439 & 8 & 0.8552 & 3 \\
000651 & 1.0000 & 1 & 0.7569 & 9 & 0.8437 & 2 & 1.0000 & 1 \\
000776 & 0.5661 & 16 & 0.5155 & 19 & 0.1000 & 18 & 0.3828 & 15 \\
000858 & 0.7747 & 10 & 0.7035 & 11 & 0.7695 & 5 & 0.6088 & 8 \\
000895 & 1.0000 & 1 & 0.8500 & 5 & 1.0000 & 1 & 0.8413 & 4 \\
600000 & 0.8764 & 6 & 0.8763 & 4 & 0.6563 & 7 & 0.2089 & 17 \\
600066 & 0.9411 & 4 & 0.8874 & 3 & 0.8294 & 3 & 0.8354 & 5 \\
600068 & 0.7181 & 13 & 0.6829 & 13 & 0.5800 & 12 & 0.5126 & 11 \\
600089 & 0.9732 & 2 & 0.5853 & 17 & 0.5538 & 13 & 0.9030 & 2 \\
600104 & 0.8395 & 7 & 0.8395 & 6 & 0.5968 & 10 & 0.4244 & 12 \\
600111 & 0.7228 & 11 & 0.6857 & 12 & 0.3937 & 17 & 0.5600 & 9 \\
600115 & 0.8195 & 9 & 0.8195 & 7 & 0.5230 & 14 & 0.2061 & 18 \\
600188 & 0.9457 & 3 & 0.9457 & 2 & 0.7819 & 4 & 0.5534 & 10 \\
600196 & 0.7223 & 12 & 0.5929 & 16 & 0.6234 & 9 & 0.6445 & 7 \\
600660 & 1.0000 & 1 & 1.0000 & 1 & 1.0000 & 1 & 0.7849 & 6 \\
600690 & 0.6980 & 14 & 0.6051 & 14 & 0.5881 & 11 & 0.3891 & 14 \\
600741 & 0.8348 & 8 & 0.8188 & 8 & 0.6974 & 6 & 0.4068 & 13 \\
600893 & 0.6146 & 15 & 0.5961 & 15 & 0.4432 & 15 & 0.2339 & 16 \\
\hline
\end{tabular}

TABLE 5. The correlation of efficiencies and rankings under the financial orientation.

\begin{tabular}{lllll}
\hline \hline \multicolumn{5}{c}{ Panel A: The correlations of the efficiencies computed by different models } \\
\hline Correlation coefficient & Model (2.12) & Model $(2.17)(t=1)$ & Model $(2.17)(t=2)$ & Model $(2.17)(t=3)$ \\
Model $(2.12)$ & 1.0000 & & & \\
Model $(2.17)(t=1)$ & 0.6140 & 1.0000 & 1.0000 & \\
Model $(2.17)(t=2)$ & 0.7071 & 0.7819 & 0.6376 & 1.0000 \\
Model $(2.17)(t=3)$ & 0.5222 & 0.3398 & & \\
\hline \multicolumn{5}{c}{ Panel B: The correlations of the rankings computed by different models } \\
\hline Correlation coefficient & Model $(2.12)$ & Model $(2.17)(t=1)$ & Model $(2.17)(t=2)$ & Model $(2.17)(t=3)$ \\
Model $(2.12)$ & 1.0000 & & & \\
Model $(2.17)(t=1)$ & 0.5517 & 1.0000 & 1.0000 & 1.0000 \\
Model $(2.17)(t=2)$ & 0.6262 & 0.7816 & 0.6199 & \\
Model $(2.17)(t=3)$ & 0.5121 & 0.3013 &
\end{tabular}

which is different from the conclusion in Table 3. More importantly, from the results in Panel B of Table 5, we can see that the conclusion of portfolio ranking is coincident with that of portfolio efficiency. That is to say, the social responsibility constraints can both affect the portfolio efficiency and the portfolio ranking.

Table 6 shows the portfolio efficiency and ranking derived from Models (2.13) to (2.18). Since Models (2.13) and (2.18) are both the social responsibility-oriented DEA models, therefore portfolio managers will measure the portfolio efficiency at a given financial level, i.e., they pay more attention to the performance of social responsibility rather than that of portfolio return. Similarly, we also provide the correlation test shown in Table 7 . 
TABle 6. Portfolio efficiency and its ranking under the social responsibility orientation.

\begin{tabular}{|c|c|c|c|c|c|c|c|c|}
\hline \multirow[t]{3}{*}{ Portfolio } & \multirow{2}{*}{\multicolumn{2}{|c|}{ Model (2.13) }} & \multicolumn{6}{|c|}{ Model (2.18) } \\
\hline & & & \multicolumn{2}{|c|}{$t=1$} & \multicolumn{2}{|c|}{$t=2$} & \multicolumn{2}{|c|}{$t=3$} \\
\hline & Efficiency & Ranking & Efficiency & Ranking & Efficiency & Ranking & Efficiency & Ranking \\
\hline 000001 & 1.0000 & 1 & 0.9904 & 4 & 0.9386 & 2 & 0.8718 & 4 \\
\hline 000002 & 1.0000 & 1 & 1.0000 & 1 & 1.0000 & 1 & 1.0000 & 1 \\
\hline 000568 & 0.9592 & 8 & 0.9024 & 12 & 0.8989 & 3 & 0.9114 & 2 \\
\hline 000651 & 1.0000 & 1 & 0.8182 & 17 & 0.6552 & 5 & 1.0000 & 1 \\
\hline 000776 & 0.9948 & 2 & 0.9948 & 2 & 0.7680 & 4 & 0.7238 & 5 \\
\hline 000858 & 0.6351 & 15 & 0.5690 & 18 & 0.5247 & 10 & 0.6351 & 6 \\
\hline 000895 & 1.0000 & 1 & 0.8649 & 15 & 1.0000 & 1 & 0.9036 & 3 \\
\hline 600000 & 0.9711 & 6 & 0.9711 & 7 & 0.5432 & 9 & 0.6159 & 8 \\
\hline 600066 & 0.9605 & 7 & 0.9605 & 8 & 0.5167 & 11 & 0.5054 & 11 \\
\hline 600068 & 0.8237 & 14 & 0.8237 & 16 & 0.4776 & 13 & 0.4429 & 13 \\
\hline 600089 & 0.9899 & 4 & 0.9800 & 5 & 0.5688 & 7 & 0.4334 & 14 \\
\hline 600104 & 0.8809 & 13 & 0.8809 & 14 & 0.4208 & 15 & 0.4161 & 15 \\
\hline 600111 & 0.9733 & 5 & 0.9733 & 6 & 0.3099 & 17 & 0.2401 & 19 \\
\hline 600115 & 0.8819 & 12 & 0.8819 & 13 & 0.6307 & 6 & 0.5395 & 10 \\
\hline 600188 & 0.9590 & 9 & 0.9590 & 9 & 0.1581 & 18 & 0.2966 & 18 \\
\hline 600196 & 0.9334 & 10 & 0.9334 & 10 & 0.4837 & 12 & 0.4466 & 12 \\
\hline 600660 & 1.0000 & 1 & 1.0000 & 1 & 1.0000 & 1 & 0.6323 & 7 \\
\hline 600690 & 0.9217 & 11 & 0.9217 & 11 & 0.5497 & 8 & 0.5944 & 9 \\
\hline 600741 & 0.4080 & 16 & 0.0512 & 19 & 0.3649 & 16 & 0.3854 & 16 \\
\hline 600893 & 0.9928 & 3 & 0.9928 & 3 & 0.4592 & 14 & 0.3295 & 17 \\
\hline
\end{tabular}

TABLE 7. The correlation of efficiencies and rankings under the social responsibility orientation.

\begin{tabular}{|c|c|c|c|c|}
\hline \multicolumn{5}{|c|}{ Panel A: The correlations of the efficiencies computed by different models } \\
\hline Correlation coefficient & Model (2.13) & Model (2.18) $(t=1)$ & Model (2.18) $(t=2)$ & Model (2.18) $(t=3)$ \\
\hline Model (2.13) & 1.0000 & & & \\
\hline Model $(2.18)(t=1)$ & 0.9517 & 1.0000 & & \\
\hline Model (2.18) $(t=2)$ & 0.3773 & 0.2709 & 1.0000 & \\
\hline Model $(2.18)(t=3)$ & 0.2877 & 0.1322 & 0.8404 & 1.0000 \\
\hline \multicolumn{5}{|c|}{ Panel B: The correlations of the rankings computed by different models } \\
\hline Correlation coefficient & Model (2.13) & Model (2.18) $(t=1)$ & Model (2.18) $(t=2)$ & Model $(2.18)(t=3)$ \\
\hline Model (2.13) & 1.0000 & & & \\
\hline Model $(2.18)(t=1)$ & 0.6827 & 1.0000 & & \\
\hline Model (2.18) $(t=2)$ & 0.6050 & 0.2884 & 1.0000 & \\
\hline Model $(2.18)(t=3)$ & 0.4414 & 0.0247 & 0.8879 & 1.0000 \\
\hline
\end{tabular}

Table 7 indicates that there is difference between Models (2.13) and (2.18), and this difference is more obvious in the third time horizon compared to the other two evaluation periods (i.e., $t=1$ and $t=2$ ). This conclusion is consistent with that obtained in Table 5 .

Table 8 shows the portfolio efficiency and ranking derived from Models (2.14) and (2.19). Using the results in Table 8, the correlation test shown in Table 9 can be obtained.

Table 9 shows that the social responsibility constraints has an impact on the portfolio efficiency and ranking derived from Models (2.14) to (2.19), which is consistent with that conclusion in Tables 5 and 7. Furthermore, 
TABLE 8. Portfolio efficiency and its ranking under the non-orientation.

\begin{tabular}{lllllllll}
\hline \hline \multirow{2}{*}{ Portfolio } & \multicolumn{2}{c}{ Model $(2.14)$} & \multicolumn{6}{c}{ Model $(2.19)$} \\
\cline { 2 - 8 } & \multicolumn{2}{c}{} & \multicolumn{2}{c}{$t=1$} & \multicolumn{2}{c}{$t=2$} & \multicolumn{2}{c}{$t=3$} \\
\cline { 2 - 8 } & Efficiency & Ranking & Efficiency & Ranking & Efficiency & Ranking & Efficiency & Ranking \\
\hline 000001 & 1.0000 & 1 & 0.7833 & 13 & 0.6919 & 5 & 0.5654 & 11 \\
000002 & 1.0000 & 1 & 1.0000 & 1 & 1.0000 & 1 & 1.0000 & 1 \\
000568 & 0.9376 & 6 & 0.8500 & 8 & 0.7861 & 2 & 0.9122 & 2 \\
000651 & 1.0000 & 1 & 0.8317 & 10 & 0.7713 & 3 & 1.0000 & 1 \\
000776 & 0.7831 & 13 & 0.7577 & 17 & 0.4499 & 17 & 0.6128 & 9 \\
000858 & 0.7323 & 15 & 0.6500 & 18 & 0.6577 & 7 & 0.7017 & 7 \\
000895 & 1.0000 & 1 & 0.9167 & 5 & 1.0000 & 1 & 0.8821 & 3 \\
600000 & 0.9382 & 5 & 0.9382 & 3 & 0.7179 & 4 & 0.4926 & 14 \\
600066 & 0.9665 & 4 & 0.9324 & 4 & 0.6874 & 6 & 0.7340 & 5 \\
600068 & 0.7777 & 14 & 0.7642 & 16 & 0.5566 & 13 & 0.6037 & 10 \\
600089 & 0.9866 & 2 & 0.7923 & 12 & 0.5808 & 11 & 0.7131 & 6 \\
600104 & 0.8819 & 7 & 0.8819 & 6 & 0.5353 & 14 & 0.4917 & 15 \\
600111 & 0.8585 & 9 & 0.8389 & 9 & 0.3798 & 18 & 0.4585 & 17 \\
600115 & 0.8618 & 8 & 0.8618 & 7 & 0.5870 & 9 & 0.5098 & 13 \\
600188 & 0.9729 & 3 & 0.9729 & 2 & 0.5018 & 15 & 0.4800 & 16 \\
600196 & 0.8528 & 10 & 0.7743 & 14 & 0.5735 & 12 & 0.6260 & 8 \\
600660 & 1.0000 & 1 & 1.0000 & 1 & 1.0000 & 1 & 0.7577 & 4 \\
600690 & 0.8200 & 11 & 0.7742 & 15 & 0.5869 & 10 & 0.5436 & 12 \\
600741 & 0.6855 & 16 & 0.5251 & 19 & 0.5909 & 8 & 0.4552 & 18 \\
600893 & 0.8073 & 12 & 0.7980 & 11 & 0.4987 & 16 & 0.3683 & 19 \\
\hline
\end{tabular}

TABLE 9. The correlations of efficiencies and rankings under the non-orientation.

\begin{tabular}{lllll}
\hline \hline \multicolumn{5}{c}{ Panel A: The correlations of the efficiencies computed by different models } \\
\hline Correlation coefficient & Model (2.14) & Model (2.19) $(t=1)$ & Model $(2.19)(t=2)$ & Model $(2.19)(t=3)$ \\
Model (2.14) & 1.0000 & & & \\
Model (2.19) $(t=1)$ & 0.7940 & 1.0000 & 1.0000 & \\
Model (2.19) $(t=2)$ & 0.5848 & 0.4595 & 0.7584 & 1.0000 \\
Model (2.19) $(t=3)$ & 0.5367 & 0.3147 & & \\
\hline \multicolumn{5}{c}{ Panel B: The correlations of the rankings computed by different models } \\
\hline Correlation coefficient & Model (2.14) & Model (2.19) $(t=1)$ & Model $(2.19)(t=2)$ & Model $(2.19)(t=3)$ \\
Model (2.14) & 1.0000 & & & \\
Model (2.19) $(t=1)$ & 0.7534 & 1.0000 & 1.0000 & 1.0000 \\
Model (2.19) $(t=2)$ & 0.5537 & 0.3836 & 0.6960 & \\
Model $(2.19)(t=3)$ & 0.5121 & 0.2271 &
\end{tabular}

compared with the other two evaluation periods (i.e., $t=1$ and $t=2$ ), the difference between Models (2.14) and (2.19) in the third time horizon is more obvious.

Similar to Figures 3-5, we will further discuss the improvements of the expectation and variance of portfolio return/social responsibility score. For the limitation of space, we only show the improvement effects within the framework of Models (2.14) and (2.19). Based on the comparison scheme shown in Section 3.1 (note that the difference is that here we use Models (2.14) and (2.19) to respectively replace Models (2.5) and (2.9), and also discuss the improvements of the expectation and variance of social responsibility score), we can similarly obtain 

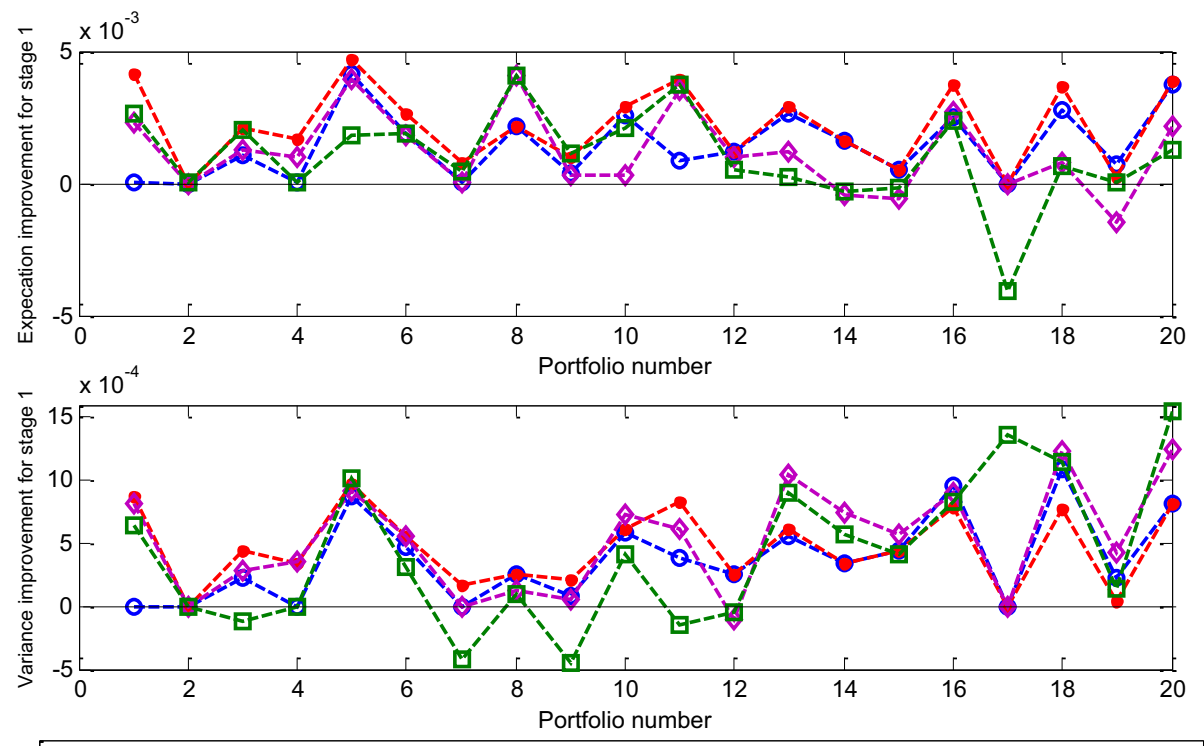

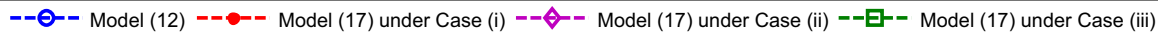

FiguRE 6 . The improvements of portfolio returns in the first time horizon.

the improvement of the expectation and variance of portfolio return and social responsibility score. The specific results are shown in Figures 6-11.

From Figures 6 to 8, we find that compared with Model (2.19), the multi-horizon Model (2.14) not only can take into account the performance of both portfolio return and social responsibility score in the different periods, but also provide a global improvement strategy for the inefficient portfolio. The improvement strategy can improve the expectation and variance of portfolio returns in each time horizon. Apparently, these conclusions in Figures $6-8$ are consistent with these in Figures 3-5.

In addition to this, the improvement effect of social responsibility score is also provided here. The detailed results are shown in Figures 9-11.

In Figures 9-11, the global improvement strategy provided by Model (2.14) can improve the performance of social responsibility score in the different time horizons, whereas the single-horizon Model (2.19) cannot. This conclusion is consistent with that in Figures 6-8.

Combined the results in Figures 6-11, we can conclude that the improvement strategies derived from the multi-horizon models can improve the expectation and variance of both portfolio returns and social responsibility scores. These conclusions further illustrate the rationality of the multi-horizon models proposed in this paper.

In order to further investigate the impact of social responsibility on the portfolio efficiency and its ranking, the correlation of the portfolio efficiencies/rankings derived from the above multi-horizon models (i.e., Models (2.5), (2.12)-(2.14)) will be examined. The specific results are shown in Table 10.

In Table 10, except for Model (2.5), the other three models (i.e., Models (2.12)-(2.14)) have all considered the performance of the social responsibility. As shown in Table 10, there is larger difference between Models (2.5) and (2.12)-(2.14) in terms of the portfolio efficiency and ranking. In particular, the correlation between Models (2.5) and (2.13) is lower (i.e., the correlation of efficiencies is 0.0211 , and the correlation of rankings is 0.1822). The results in Table 10 also show that the social responsibility has a greater impact on the portfolio efficiency and its ranking, especially when the portfolio managers are more inclined to the performance of social responsibility. The above results can further provide the strategic support for the different portfolio managers, 

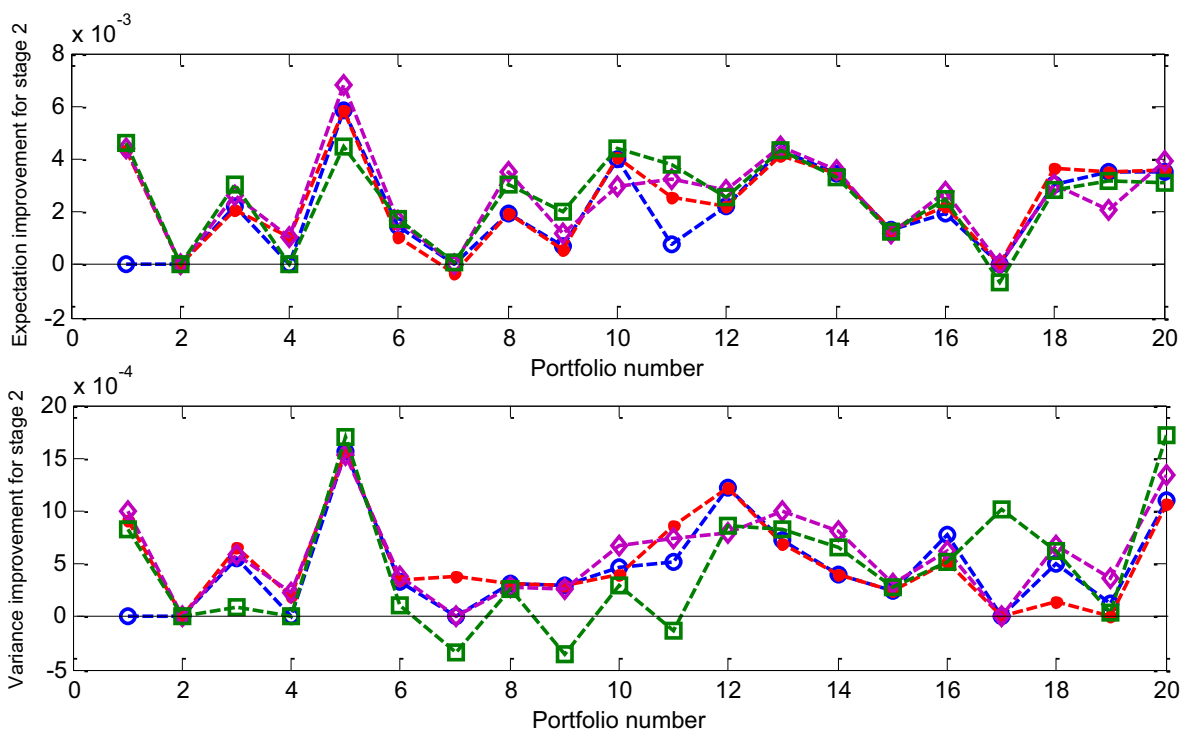

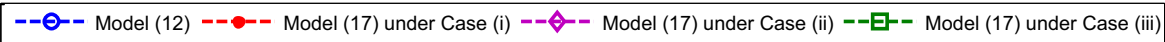

FiguRE 7. The improvements of portfolio returns in the second time horizon.
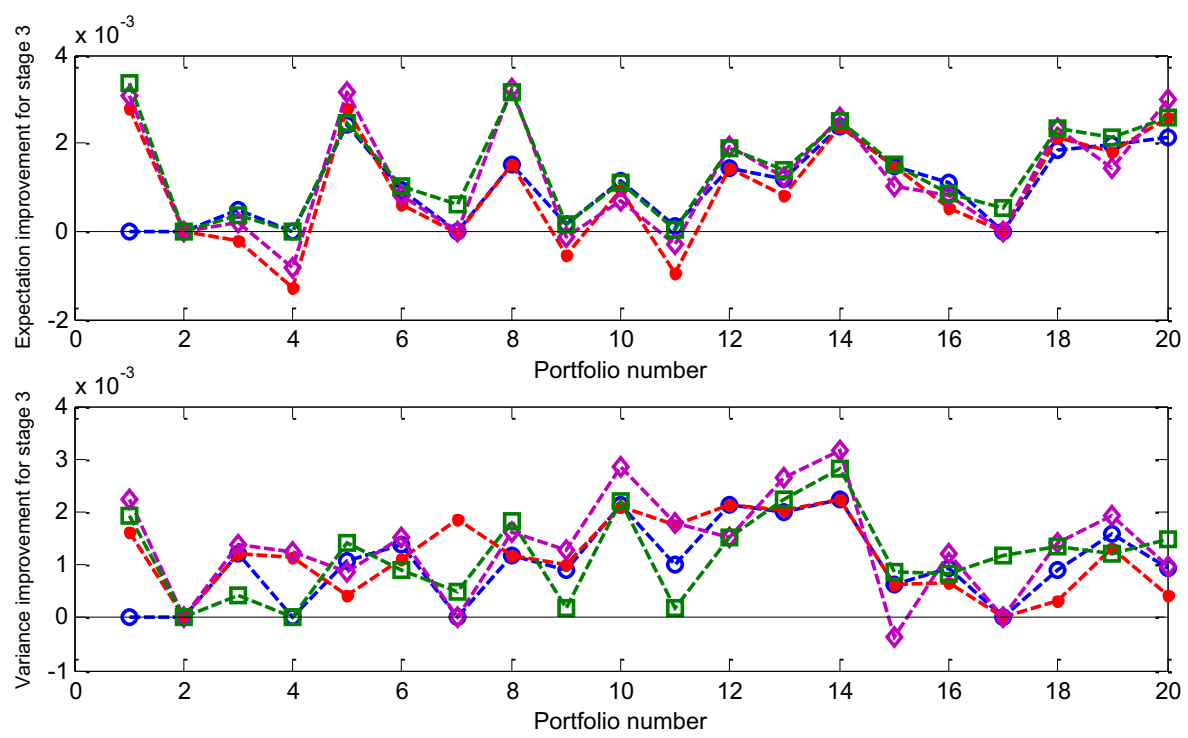

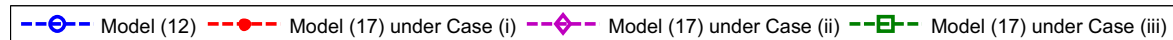

FiguRE 8 . The improvements of portfolio returns in the third time horizon. 

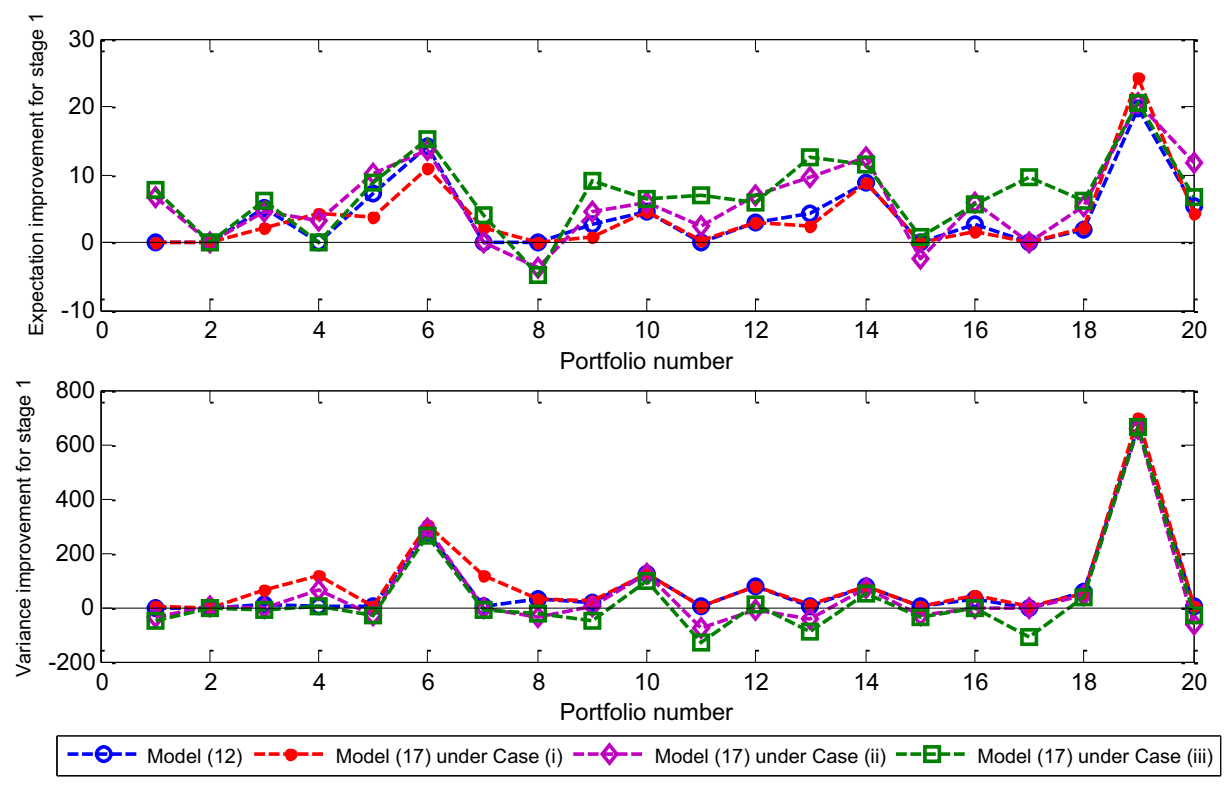

FIgURE 9. The improvements of social responsibility scores in the first time horizon.
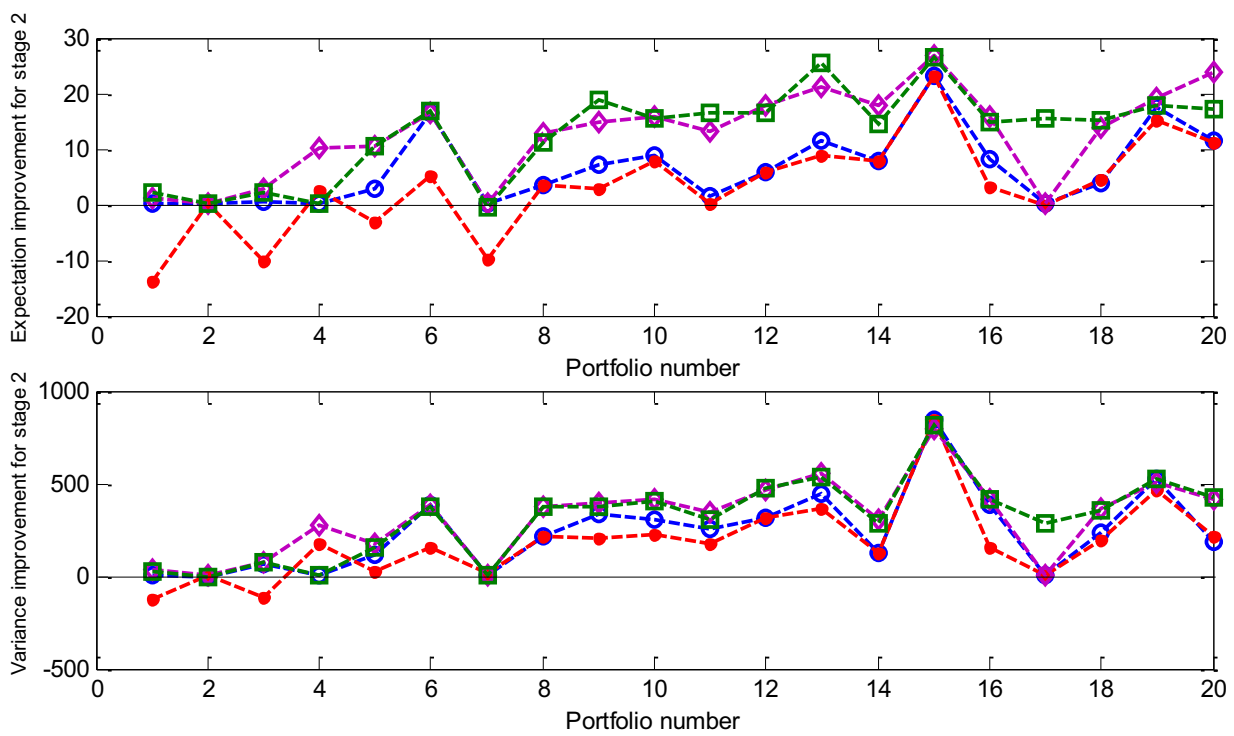

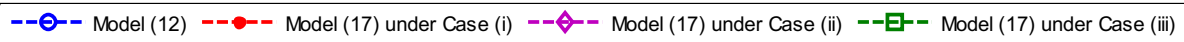

FIGURE 10. The improvements of social responsibility scores in the second time horizon. 

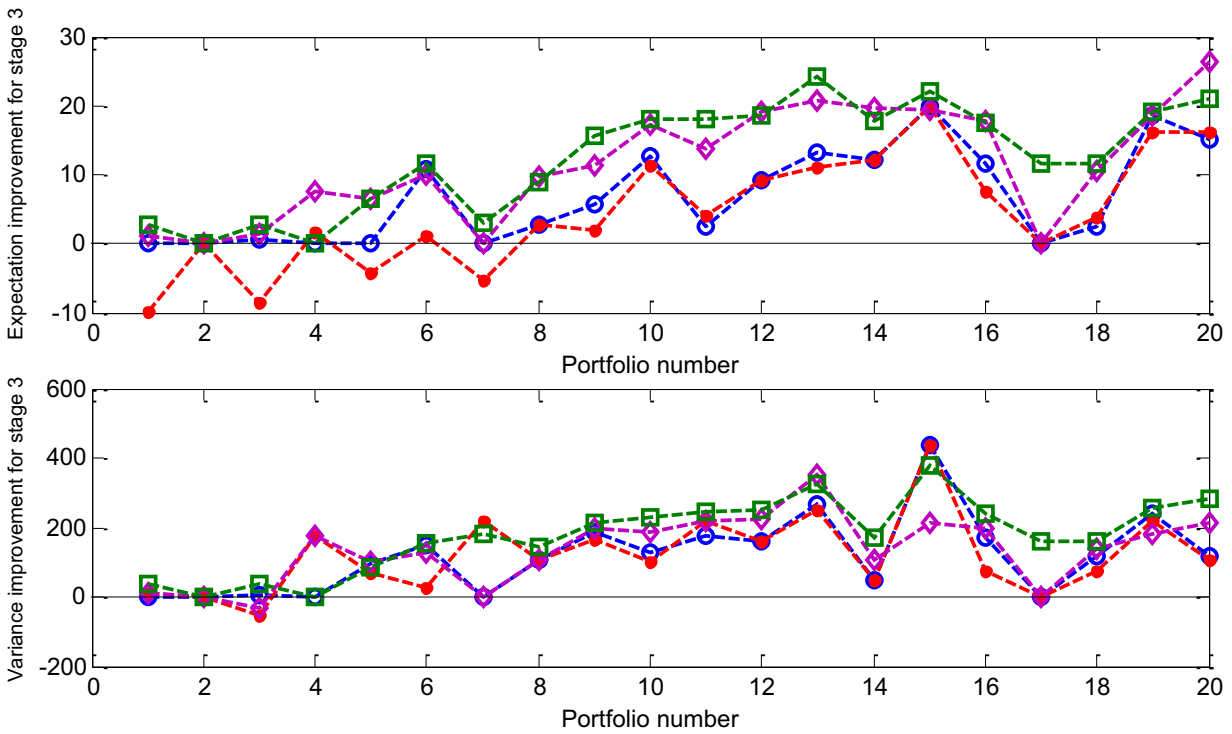

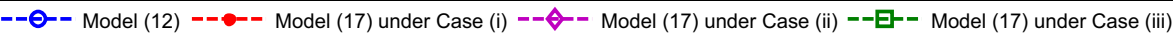

FiguRE 11. The improvements of social responsibility scores in the third time horizon.

TABLE 10. The correlation of efficiencies and rankings of portfolios.

\begin{tabular}{lllll}
\hline \hline \multicolumn{5}{c}{ Panel A: The correlations of the efficiencies computed by different models } \\
\hline Correlation coefficient & Model (2.5) & Model (2.12) & Model (2.13) & Model (14) \\
Model (2.5) & 1.0000 & & & \\
Model (2.12) & 0.7204 & 1.0000 & 1.0000 & \\
Model (2.13) & 0.0211 & 0.1926 & 0.7349 & 1.0000 \\
Model (2.14) & 0.5062 & 0.8030 & & \\
\hline \multicolumn{5}{c}{ Panel B: The correlations of the rankings computed by different models } \\
\hline Correlation coefficient & Model (2.5) & Model (2.12) & Model (2.13) & Model (2.14) \\
Model (2.5) & 1.0000 & & & \\
Model (2.12) & 0.7536 & 1.0000 & 1.0000 & \\
Model (2.13) & 0.1822 & 0.4404 & 0.6885 & 1.0000 \\
Model (2.14) & 0.5785 & 0.8769 & & \\
\hline
\end{tabular}

i.e., the portfolio managers can choose a suitable management strategy according to their preference for social responsibility.

\section{Conclusions}

The existing portfolio evaluation studies that consider social responsibility performance are still limited to static evaluations, and also ignore the correlation between portfolios. However, for portfolio managers, they often need to consider the performance of portfolios in different time horizons, so as to formulate a global management strategy. In this paper, we incorporate the financial and non-financial indicators to clarify the input-output process of portfolios under the multi-horizon framework. Further, we construct the corresponding stochastic output possibility sets both with and without social responsibility constraints. We use the mean and variance measures to derive the corresponding deterministic output possibility sets under the mean-variance 
criterion. We employ the direction distance function to construct the multi-horizon diversification DEA models under different situations, including financial-oriented, social responsibility-oriented and non-oriented models. Finally, we take the 20 component stocks of China ESG100 Index to verify the effectiveness of the proposed models. It is aimed to show the difference between the multi-horizon models and the single-horizon models, and further discuss the impact of social responsibility on the portfolio efficiency and its ranking. The empirical results show that compared with the single-horizon models, the improvement strategies obtained from the multihorizon models can simultaneously improve the expectation and variance of both portfolio return and social responsibility score in different periods. Besides, we also find that the social responsibility score has a greater impact on the portfolio efficiency and its ranking, especially for portfolio managers pay more attention to the performance of social responsibility.

Acknowledgements. This research is supported by the National Natural Science Foundation of China (Nos. 71771082 and 71801091), Hunan Provincial Natural Science Foundation of China (No. 2020JJ5377), China Postdoctoral Science Foundation funded project (No. 2020M682577), and Hunan Key Laboratory of Macroeconomic Big Data Mining and its Application.

\section{REFERENCES}

[1] O. Abdelsalam, M. Duygun, J.C. Matallín-Sáez and E. Tortosa-Ausina, Do ethics imply persistence? The case of Islamic and socially responsible funds. J. Banking Finance 40 (2014) 182-194.

[2] E. Allevi, A. Basso, F. Bonenti, G. Oggioni and R. Riccardi, Measuring the environmental performance of green SRI funds: a DEA approach. Energy Econ. 79 (2019) 32-44.

[3] A. Basso and S. Funari, A data envelopment analysis approach to measure the mutual fund performance. Eur. J. Oper. Res. 135 (2001) 477-492.

[4] A. Basso and S. Funari, Measuring the performance of ethical mutual funds: a DEA approach. J. Oper. Res. Soc. 54 (2003) $521-531$.

[5] A. Basso and S. Funari, Constant and variable returns to scale DEA models for socially responsible investment funds. Eur. J. Oper. Res. 235 (2014) 775-783.

[6] A. Basso and S. Funari, The role of fund size in the performance of mutual funds assessed with DEA models. Eur. J. Finance 23 (2017) 457-473.

[7] C. Belu, Ranking corporations based on sustainable and socially responsible practices. A data envelopment analysis (DEA) approach. Sustainable Dev. 17 (2009) 257-268.

[8] M. Branda, Diversification-consistent data envelopment analysis based on directional-distance measures. Omega 52 (2015) $65-76$.

[9] W. Briec and K. Kerstens, Multi-horizon Markowitz portfolio performance appraisals: a general approach. Omega 37 (2009) $50-62$.

[10] W. Briec, K. Kerstens and J.B. Lesourd, Single-period Markowitz portfolio selection, performance gauging, and duality: a variation on the Luenberger shortage function. J. Optim. Theory App. 120 (2004) 1-27.

[11] W. Briec, K. Kerstens and O. Jokung, Mean-variance-skewness portfolio performance gauging: a general shortage function and dual approach. Manage. Sci. 53 (2007) 135-149.

[12] Z. Chen and R. Lin, Mutual fund performance evaluation using data envelopment analysis with new risk measures. Or Spectr. 28 (2006) 375-398.

[13] W. Chen, Y. Gai and P. Gupta, Efficiency evaluation of fuzzy portfolio in different risk measures via DEA. Ann. Oper. Res. 269 (2018) 103-127.

[14] X. Chen, J. Zhang and H. Zeng, Is corporate environmental responsibility synergistic with governmental environmental responsibility? Evidence from China. Bus. Strategy Environ. 29 (2020) 3669-3686.

[15] H. Choi and D. Min, Efficiency of well-diversified portfolios: evidence from data envelopment analysis. Omega 73 (2017) $104-113$.

[16] H. Ding, Z. Zhou, H. Xiao, C. Ma and W. Liu, Performance evaluation of portfolios with margin requirements. Math. Prob. Eng. (2014) 1-8.

[17] D.U. Galagedera, Modelling social responsibility in mutual fund performance appraisal: a two-stage data envelopment analysis model with non-discretionary first stage output. Eur. J. Oper. Res. 273 (2019) 376-389.

[18] G.N. Gregoriou, K. Sedzro and J. Zhu, Hedge fund performance appraisal using data envelopment analysis. Eur. J. Oper. Res. 164 (2005) 555-571.

[19] S. Han, W. You and S. Nan, Zombie firms, external support and corporate environmental responsibility: evidence from China. J. Cleaner Prod. 212 (2019) 1499-1517.

[20] T. Joro and P. Na, Portfolio performance evaluation in a mean-variance-skewness framework. Eur. J. Oper. Res. 175 (2006) 446-461. 
[21] J.D. Lamb and K.H. Tee, Data envelopment analysis models of investment funds. Eur. J. Oper. Res. 216 (2012) $687-696$.

[22] R. Lin and Z. Li, Directional distance based diversification super-efficiency DEA models for mutual funds. Omega 97 (2020) 102096.

[23] R. Lin, Z. Chen, Q. Hu and Z. Li, Dynamic network DEA approach with diversification to multi-period performance evaluation of funds. Or Spectr. 39 (2017) 821-860.

[24] W. Liu, Z. Zhou, D. Liu and H. Xiao, Estimation of portfolio efficiency via DEA. Omega 52 (2015) 107-118.

[25] S. Lozano and E. Gutiérrez, Data envelopment analysis of mutual funds based on second-order stochastic dominance. Eur. J. Oper. Res. 189 (2008) 230-244.

[26] R. Makni, O. Benouda and E. Delhoumi, Large scale analysis of Islamic equity funds using a meta-frontier approach with data envelopment analysis. Res. Int. Bus. Finance 34 (2015) 324-337.

[27] H. Markowitz, Portfolio selection. J. Finance 7 (1952) 77-91.

[28] M.R. Morey and R.C. Morey, Mutual fund performance appraisals: a multi-horizon perspective with endogenous benchmarking. Omega 27 (1999) 241-258.

[29] B.P.S Murthi, Y.K. Choi and P. Desai, Efficiency of mutual funds and portfolio performance measurement: A non-parametric approach. Eur. J. Oper. Res. 98 (1997) 408-418.

[30] B. Pérez Gladish, P.M. Rodríguez, B. M'Zali and P. Lang, Mutual funds efficiency measurement under financial and social responsibility criteria. J. MultiCriteria Decis. Anal. 20 (2013) 109-125.

[31] A.C. Tarnaud and H. Leleu, Portfolio analysis with DEA: prior to choosing a model. Omega 75 (2018) 57-76.

[32] I.E. Tsolas and V. Charles, Green exchange-traded fund performance appraisal using slacks-based DEA models. Oper. Res. 15 (2015) 51-77.

[33] M. Zhong, R. Xu, X. Liao and S. Zhang, Do CSR ratings converge in China? A comparison between RKS and Hexun scores. Sustainability 11 (2019) 3921.

[34] Z. Zhou, Q. Jin, H. Xiao, Q. Wu and W. Liu, Estimation of cardinality constrained portfolio efficiency via segmented DEA. Omega 76 (2018) 28-37.

[35] Z. Zhou, H. Xiao, Q. Jin and W. Liu, DEA frontier improvement and portfolio rebalancing: an application of China mutual funds on considering sustainability information disclosure. Eur. J. Oper. Res. 269 (2018) 111-131.

[36] Z. Zhou, E. Chen, H. Xiao, T. Ren and Q. Jin, Performance evaluation of portfolios with fuzzy returns. RAIRO:OR 53 (2019) $1581-1600$. 